\title{
The Response of Hadley Circulation Extent to an Idealized Representation of Poleward Ocean Heat Transport in an Aquaplanet GCM ${ }^{0}$
}

\author{
CASEy C. Hilgenbrink And Dennis L. HaRtmann \\ Department of Atmospheric Sciences, University of Washington, Seattle, Washington
}

(Manuscript received 22 May 2018, in final form 21 September 2018)

\begin{abstract}
Deeper theoretical understanding of Hadley circulation (HC) width and the mechanisms leading to HC expansion is gained by exploring the response of a zonally symmetric slab ocean aquaplanet general circulation model (GCM) to imposed poleward ocean heat transport (OHT). Poleward OHT causes the subtropical edge of the $\mathrm{HC}$ to shift poleward by up to $3^{\circ}$ compared to its position in simulations without OHT. This $\mathrm{HC}$ widening is interpreted as being driven by a decrease in baroclinicity near the poleward edge of the $\mathrm{HC}$ and is divided into three components: a decrease in baroclinicity due to 1) a systematic poleward shift of the intertropical convergence zone (ITCZ) during the seasonal cycle that drives a decrease in the angular momentum of the $\mathrm{HC}$ and, consequently, a weakening of the vertical shear of the zonal wind; 2) an increase in subtropical static stability and the vertical extent of the HC, both of which result from OHT's effect on global-mean temperature; and 3) a relaxation of the meridional sea surface temperature (SST) gradient in the outer tropics and subtropics by OHT. Although the third mechanism contributes the most to the response of $\mathrm{HC}$ width to OHT, the contributions from the first two mechanisms each account for up to $20 \%-30 \%$ of the $\mathrm{HC}$ response. This work highlights the role of ITCZ position in producing HC expansion and in setting the climatological width of the $\mathrm{HC}$, a role which has been underappreciated. This study indicates a fundamental role for baroclinicity in limiting the poleward extent of the HC.
\end{abstract}

\section{Introduction}

The Hadley circulation (HC) is fundamental for shaping the water balance in low latitudes through its converging surface winds in the equatorial region that fuel deep convection in the intertropical convergence zone (ITCZ) and its subsiding branch in the subtropics that suppresses precipitation. Therefore, it is important to understand the factors that control the width of the HC. A comprehensive, prognostic theory for HC extent remains elusive, however (Schneider 2006; Vallis et al. 2015). This has led to ambiguities in interpreting trends in $\mathrm{HC}$ extent in simulations of future climates, even when the sign of the trend is robust. For example, simulations of the twenty-first century by the comprehensive climate models in phase 3 (Lu et al. 2007; Kang and Lu 2012) and phase 5 (Ceppi and Hartmann 2016; Davis and Birner 2017) of the Coupled Model Intercomparison

Supplemental information related to this paper is available at the Journals Online website: https://doi.org/10.1175/JCLI-D-18-0324.s1.

Corresponding author: Casey C. Hilgenbrink, chilge@uw.edu
Project (CMIP) consistently predict a poleward expansion of the $\mathrm{HC}$ in response to future anthropogenic emissions of greenhouse gases, although the magnitude of the trend is uncertain. This HC widening is qualitatively reproduced in idealized simulations of global warming using both dry dynamical core (Butler et al. 2010; Tandon et al. 2013) and aquaplanet models (Frierson et al. 2007; Levine and Schneider 2015; Shaw and Voigt 2016). Many plausible drivers for this $\mathrm{HC}$ widening have been proposed, including an increase in subtropical static stability and the height of the tropical tropopause (Lu et al. 2007; Kang and Lu 2012) and an increase in the phase speed of midlatitude eddies (Lu et al. 2008; Ceppi and Hartmann 2013).

An axisymmetric, angular-momentum-conserving $\mathrm{HC}$ (e.g., Held and Hou 1980) is linearly baroclinically unstable (e.g., Phillips 1954), which has led to theories for $\mathrm{HC}$ extent involving control of $\mathrm{HC}$ extent by baroclinic eddy activity. Although several formulations of such theories have been proposed (Held et al. 2000; Korty and Schneider 2008; Levine and Schneider 2015), they all generally predict that the poleward extent of the $\mathrm{HC}$ is a function of the meridional temperature gradient (and hence of the vertical shear of the zonal wind), static 
stability, and the height of the tropopause (due to its control on the vertical extent of the HC), since these quantities enter into measures of baroclinicity (e.g., Eady 1949; Phillips 1954; Schneider 2006). Indeed, increased subtropical static stability (Walker and Schneider 2006; Frierson et al. 2007; Davis et al. 2016; Son et al. 2018), increased tropopause height (Frierson et al. 2007; D'Agostino et al. 2017), and weakened subtropical meridional temperature gradients and vertical wind shears (Korty and Schneider 2008; Tandon et al. 2013; Mantsis et al. 2014; Adam et al. 2014; Levine and Schneider 2015) have each been implicated in HC expansion in models and observations. Because these quantities often vary in tandem, however, their separate effects have been difficult to untangle.

Here we examine the HC's response to an idealized representation of poleward ocean heat transport (OHT) to better understand the fundamental dynamics that control the width of the $\mathrm{HC}$ and its expansion. The reasons for choosing this forcing to study the $\mathrm{HC}$ are several. Poleward OHT is known to both increase global-mean surface temperature and modify meridional temperature gradients (Winton 2003; Herweijer et al. 2005; Rose and Ferreira 2013; Koll and Abbot 2013). Thus, the idealized OHT forcing used in this study is well suited for an examination of the relative roles of global-mean temperature (with which both subtropical static stability and the depth of the troposphere tend to increase) and meridional temperature gradients for the width of the HC. Furthermore, whereas the response of $\mathrm{HC}$ extent to forcings such as global warming (see above) and El Niño (Seager et al. 2003; Lu et al. 2008; Tandon et al. 2013) has been studied extensively in recent years, the dependence of $\mathrm{HC}$ extent on poleward OHT has received markedly less attention. Finally, from a broader climate dynamics perspective, previous research has shown poleward OHT to be important in modulating global-mean surface temperature and meridional temperature gradients, the spatial distribution of clouds and global-mean albedo (Herweijer et al. 2005; Koll and Abbot 2013), the position of the ITCZ (Clement 2006), and the strength of the HC (Clement 2006; Levine and Schneider 2011; Knietzsch et al. 2015). Characterizing the response of $\mathrm{HC}$ width to OHT will broaden this understanding of how OHT modulates surface climate.

Herweijer et al. (2005) studied the effects of OHT on global temperatures using three different comprehensive coupled climate models: two with slab oceans, each with and without an implicit representation of OHT, and a third in which ocean currents were reduced and increased by $50 \%$. Although the authors did not discuss changes to HC extent, they showed implicitly in their Fig. 9 that OHT causes an annual-mean poleward expansion of the HC. Using a similar set of slab ocean simulations, Clement (2006) showed that this widening effect of OHT on the HC occurs during both winter and summer (implicit in her Fig. 1). More recently, Knietzsch et al. (2015) found that the HC widens in intermediate-complexity aquaplanet simulations forced by systematic increases in OHT; the authors attributed this widening to a weakening of the meridional temperature gradient across the $\mathrm{HC}$, although they did not invoke a dynamical mechanism to explain this response. Finally, using an idealized moist atmospheric model coupled to a one-dimensional representation of OHT via surface wind stress and surface temperature gradients, Levine and Schneider (2011) found that for climates as warm as today and colder, OHT causes the HC edge to shift poleward by several degrees. Later, Levine and Schneider (2015) interpreted this response as resulting from a decrease in baroclinicity near the HC edge driven by a weakening of the surface temperature gradient there. It is important to note that their simulations used a gray radiation scheme, and therefore did not include OHT's warming effect on global-mean surface temperature (or any HC expansion associated with this warming), since water vapor and cloud radiative feedbacks are key in producing this warming (Herweijer et al. 2005; Rose and Ferreira 2013; Rencurrel and Rose 2018).

To summarize, previous research indicates poleward OHT causes HC expansion, but this expansion has not been fully explained. Here we explore the HC's response to an idealized representation of OHT for the dual purposes of explaining this OHT-induced $\mathrm{HC}$ widening and increasing fundamental understanding of the dynamics that govern $\mathrm{HC}$ extent.

\section{Methods}

\section{a. Atmospheric model and the idealized ocean heat transport}

We use an aquaplanet configuration of the Geophysical Fluid Dynamics Laboratory (GFDL) Atmospheric Model, version 2.1 (AM2.1; Anderson et al. 2004). This version of AM2.1 has a finite-volume dynamical core with 24 vertical hybrid pressure-sigma levels and a spatial resolution of $2.5^{\circ}$ longitude $\times 2.0^{\circ}$ latitude. The model has diurnally and seasonally varying insolation with obliquity set to $23.5^{\circ}$ and eccentricity set to zero to preserve hemispheric symmetry in the annual mean. All atmospheric constituents that could produce hemispherically asymmetric radiative forcings (e.g., ozone) are symmetrized about the equator. This configuration of AM2.1 does not include the radiative effects of aerosols. 
TABLE 1. Description of the experiments used in this study. The first column lists the experiment name, and the second column lists the slab ocean depth for that experiment. The third and fourth columns list the values of $A$ and $N$, respectively, used in (1). The last column lists the value of the globally uniform $q$ flux, if any, superimposed on the $q$ flux associated with the idealized ocean heat transport.

\begin{tabular}{|c|c|c|c|c|}
\hline Experiment name & Slab ocean depth & $A(\mathrm{PW})$ & $N$ (unitless) & Superimposed uniform $q$ flux $\left(\mathrm{W} \mathrm{m}^{-2}\right)$ \\
\hline$C T L$ & $\begin{array}{l}\text { Variable }(2.4-50 \mathrm{~m}) \text {; representative } \\
\quad \text { slab ocean depth }=12 \mathrm{~m}\end{array}$ & 0 & - & 0 \\
\hline$O H T$ & $\begin{array}{l}\text { Variable }(2.4-50 \mathrm{~m}) \text {; representative } \\
\text { slab ocean depth }=12 \mathrm{~m}\end{array}$ & 9.6649 & 6 & 0 \\
\hline OHT+UniCool & $12 \mathrm{~m}$ & 9.6649 & 6 & -3.6082 \\
\hline NarrowOHT & $12 \mathrm{~m}$ & 20.8570 & 28.85 & 0 \\
\hline NarrowOHT+UniWarm & $12 \mathrm{~m}$ & 20.8570 & 28.85 & +2.2712 \\
\hline
\end{tabular}

The atmospheric model is coupled to a slab ocean lower boundary. The slab ocean has no sea ice; sea surface temperature (SSTs) can fall below the freezing temperature without forming ice. Unless otherwise stated, the slab ocean depth is $12 \mathrm{~m}$. This slab ocean depth produces an annual-mean HC strength, meridional distribution of albedo and precipitation, and seasonal migration of ITCZ that are similar to present-day conditions (Donohoe et al. 2014). To highlight the importance of certain $\mathrm{HC}$ expansion mechanisms, we run a subset of our simulations (viz., the OHT experiments described below) for an ensemble of slab ocean depths: $2.4,6,10,12,24,36$, and $50 \mathrm{~m}$.

We compare experiments with and without an idealized representation of OHT, referred to as $O H T^{1}$ and $C T L$, respectively. The functional form of the OHT is from Rose and Ferreira (2013):

$$
\mathrm{OHT}(\phi)=A \sin \phi \cos ^{2 N} \phi,
$$

where $\phi$ is latitude, and $A$ and $N$ are parameters controlling the amplitude and meridional scale of the OHT, respectively. This OHT has no cross-equatorial component since (1) is antisymmetric about the equator. We choose $A=9.66 \mathrm{PW}$ and $N=6$ (Table 1 ) to produce an idealized OHT profile that peaks at the same amplitude and nearly the same latitude as a reanalysis-based estimate of Earth's present-day OHT that has been made antisymmetric about the equator (Fig. 1a). The OHT is imposed by prescribing its horizontal convergence as a heating term (or $q$ flux) in the slab ocean's energy budget; the $q$ flux for $O H T$ is shown in Fig. 1b in dark red. This $q$ flux has zero global mean and therefore adds no net source or sink of energy to the climate system.

All simulations are run for at least 30 years after the model reaches statistical equilibrium.

\footnotetext{
${ }^{1}$ Hereafter, when the abbreviation "OHT" is italicized, it is shorthand for "the $O H T$ experiment"; when it is not italicized, it refers to the general phrase "ocean heat transport." For consistency, other experiment names also appear in italics.
}

\section{b. Circulation diagnostics}

Two critical diagnostics in this study are the poleward extent of the HC $\phi_{H}$ and the latitude of the ITCZ $\phi_{i}$. Here, $\phi_{H}$ is defined as the latitude at which the meridional mass streamfunction at $500 \mathrm{hPa}$ first crosses zero poleward of its tropical extremum. The ITCZ latitude is defined as the upward velocity-weighted average latitude equatorward of $30^{\circ}$, that is,

$$
\phi_{i} \equiv \frac{\sum_{\left|\phi_{j}\right| \leq 30^{\circ}} \phi_{j} \tilde{\omega}_{j}^{\uparrow} \cos \phi_{j}}{\sum_{\left|\phi_{j}\right| \leq 30^{\circ}} \tilde{\omega}_{j}^{\uparrow} \cos \phi_{j}},
$$

where

$$
\tilde{\omega}^{\uparrow} \equiv\left\{\begin{array}{c}
\tilde{\omega}, \tilde{\omega}<0 \\
0, \tilde{\omega} \geq 0
\end{array},\right.
$$

$\omega$ is the pressure velocity, and the tilde indicates a massweighted vertical average. We have defined $\phi_{i}$ in this way to emphasize the connection between the ITCZ and the ascending branch of the HC, although (2) yields similar results as definitions based on the latitude of maximum tropical precipitation or on the precipitation median (sometimes referred to as the "precipitation centroid" in the literature; Frierson and Hwang 2012; Adam et al. 2016). To facilitate comparison with past and future studies, in the online supplemental material we have reproduced several key tables and figures (viz., Table 2, Figs. 5, 7) using the precipitation median to define the ITCZ position.

Section 5 discusses the seasonal cycle of $\phi_{i}$. We define the seasonal cycle of ITCZ latitude $\phi_{i, \mathrm{SC}}$ as the sum of the first five Fourier harmonics of the annual cycle regressed onto the monthly $\phi_{i}$ time series. The amplitude $\Phi_{i}$ of this seasonal cycle is then defined as

$$
\Phi_{i} \equiv \frac{1}{365 \text { days }} \int_{0 \text { days }}^{365 \text { days }}\left|\phi_{i, \mathrm{SC}}\right| d t
$$

This metric is the time-average distance of the climatological ITCZ from the equator, and has the desirable characteristic of being sensitive to poleward shifts of the climatological ITCZ during any point in the seasonal cycle. 

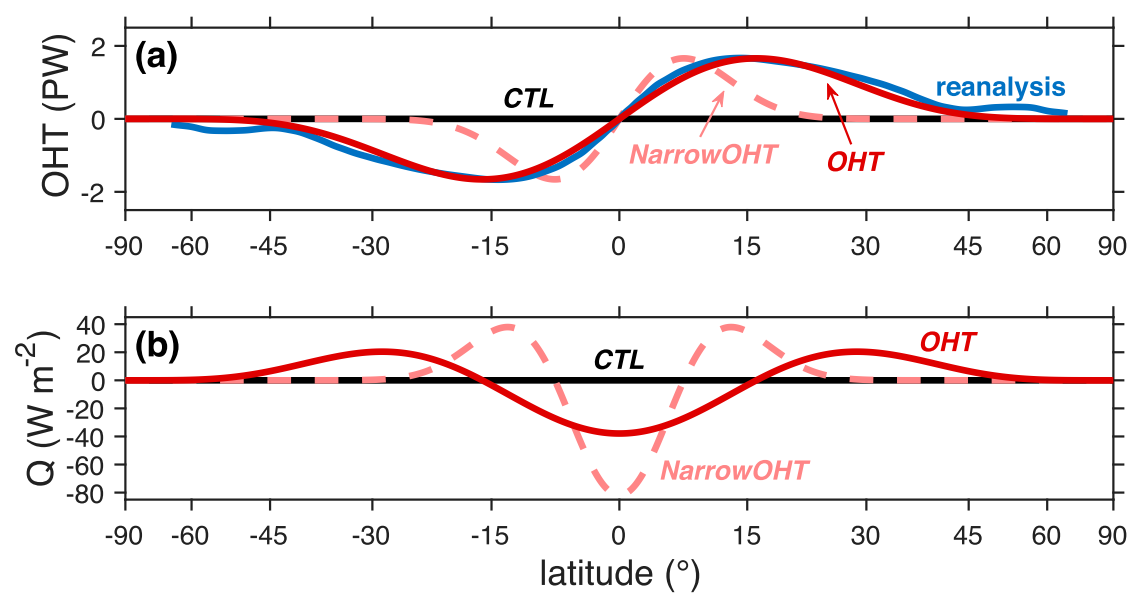

FIG. 1. (a) The imposed meridional ocean heat transport (PW) for CTL (black), OHT (unbroken dark red), and NarrowOHT (dashed light red; NarrowOHT will be described later in the paper in section 5 b). For comparison, the blue curve labeled "reanalysis" shows an estimate of Earth's meridional ocean heat transport computed from the NCEP-NCAR reanalysis by Trenberth and Caron (2001), where here this reanalysis profile has been made antisymmetric about the equator. (b) The ocean heat transport convergences or $q$ fluxes $\left(\mathrm{W} \mathrm{m}^{-2}\right)$ that correspond to the imposed ocean heat transports.

\section{Thermodynamic and kinematic response to ocean heat transport}

The annual-mean air temperature and SST responses to $O H T$ are shown in Figs. 2a-f, and the response of annual-mean global-mean SST $\overline{T_{s}}$ is shown in Table 2 .
Compared to $C T L, O H T$ causes a robust warming of $\overline{T_{s}}$ for all slab ocean depths; for our reference $(12 \mathrm{~m})$ slab ocean depth, $\overline{T_{s}}$ increases by $2.73 \mathrm{~K}$. This warming effect of OHT has been identified previously in several different climate models and has been attributed to increased greenhouse trapping resulting from convective moistening

TABLE 2. Annual-mean global-mean surface temperature, annual-mean HC extent, the amplitude of the seasonal cycle of ITCZ latitude, and their responses to the imposed forcing. Shown from left to right are experiment names, annual-mean $\overline{T_{s}}$, difference in $\overline{T_{s}}$ from respective $C T L$ run, annual-mean $\phi_{H}$, difference in $\phi_{H}$ from respective $C T L$ run, amplitude $\Phi_{i}$ of the seasonal cycle of ITCZ latitude, and difference in $\Phi_{i}$ from the respective $C T L$ run. Bold numbers indicate statistical significance at the $95 \%$ confidence level according to a twotailed $t$ test with effective sample size calculated following Bretherton et al. (1999) (note that the difference in $\Phi_{i}$ was not tested for statistical significance). In the fifth column, positive values indicate a poleward $\phi_{H}$ shift.

\begin{tabular}{lccccc}
\hline \hline \multicolumn{1}{c}{ Experiment } & \multicolumn{2}{c}{$\begin{array}{c}\text { Change in } \overline{T_{s}} \text { from } \\
T_{s}(\mathrm{~K})\end{array}$} & $\begin{array}{c}\text { Change in } \phi_{H} \text { from } \\
\text { respective } C T L \text { run }(\mathrm{K})\end{array}$ & $\begin{array}{c}\phi_{H}\left({ }^{\circ}\right) \\
\text { respective } C T L \text { run }\left(^{\circ}\right)\end{array}$ & $\begin{array}{c}\text { Change in } \Phi_{i} \text { from } \\
\left(^{\circ}\right)\end{array}$ \\
respective $C T L$ run $\left(^{\circ}\right)$
\end{tabular}

${ }^{\text {a }}$ The global-mean surface temperatures in NarrowOHT and NarrowOHT+UniWarm are statistically indistinguishable at the $95 \%$ confidence level. 
CTL
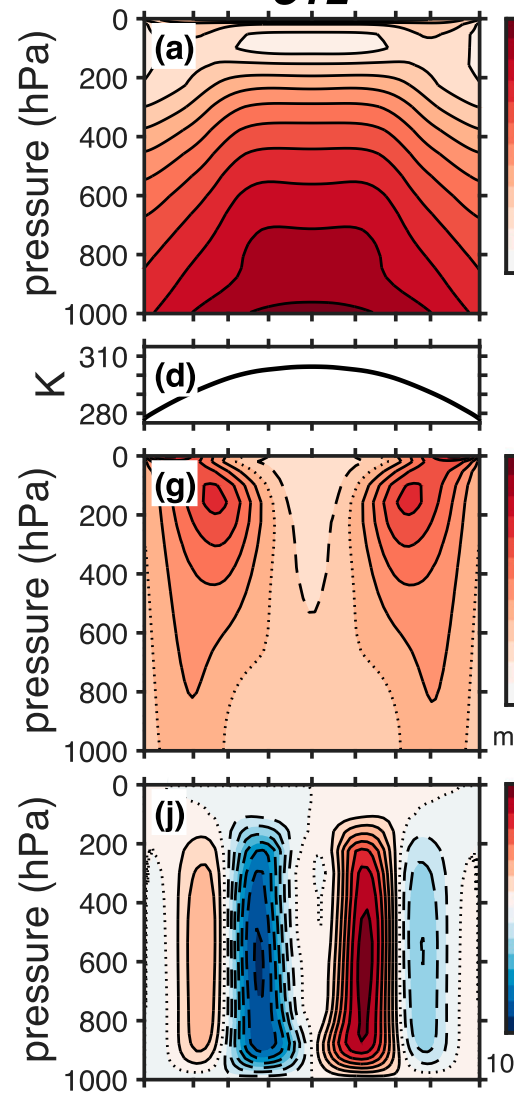$$
\begin{gathered}
T^{\prime} \omega \\
0
\end{gathered}
$$$$
\begin{array}{lr}
\text { c } & -0.02 \\
\text { జ } & 0 \\
0 & 0.02
\end{array}
$$

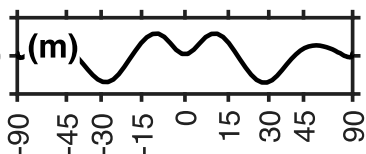

latitude $\left({ }^{\circ}\right)$
OHT
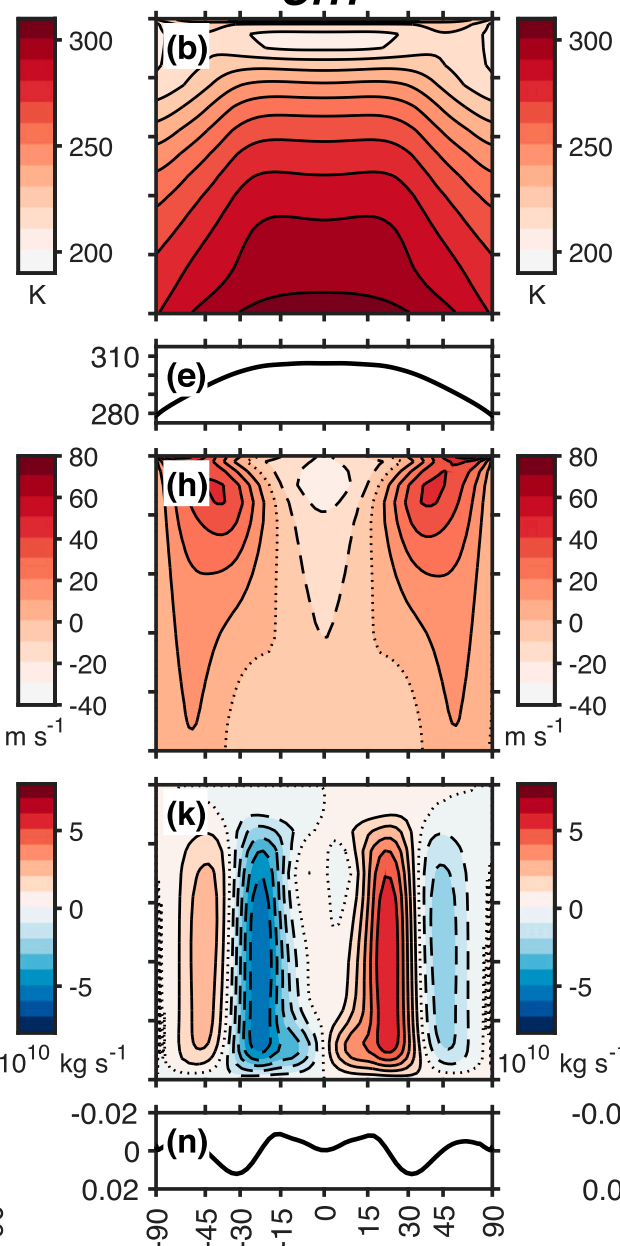

latitude $\left(^{\circ}\right)$

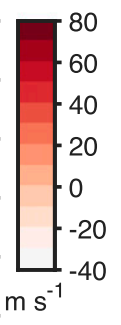

difference
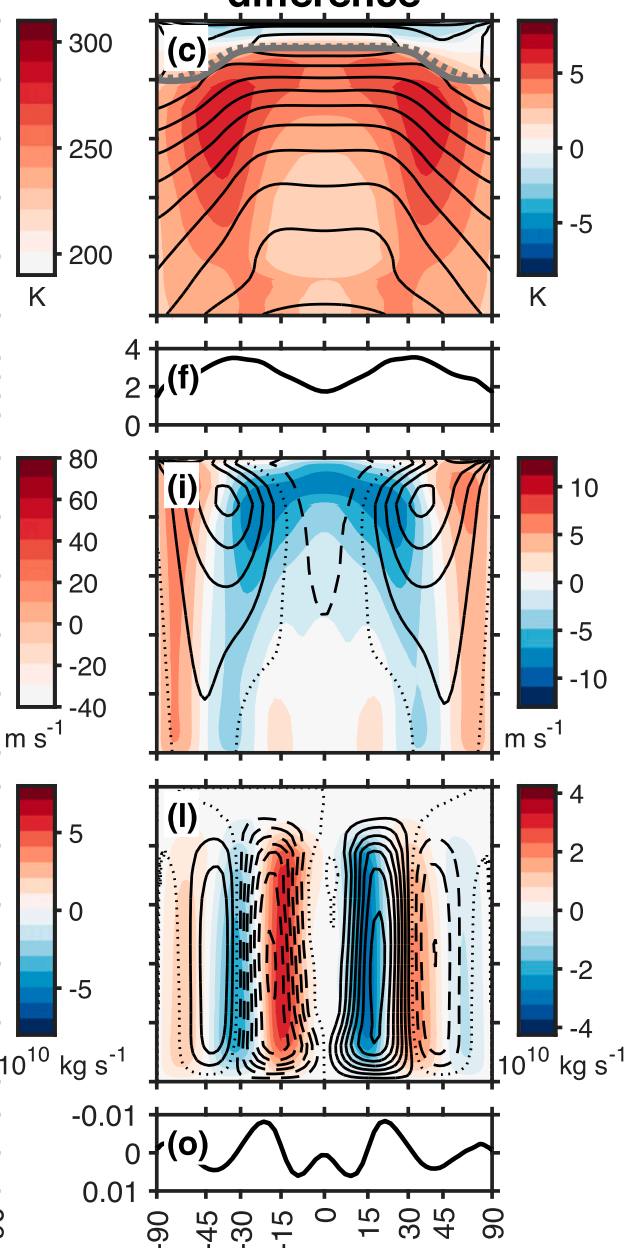

latitude $\left({ }^{\circ}\right)$

FIG. 2. Annual-mean temperature and circulation diagnostics for (left) $C T L$, (center) $O H T$, and (right) their difference. Note that both $C T L$ and $O H T$ have a slab ocean depth of $12 \mathrm{~m}$. (a),(b) Zonal-mean air temperature (K) for $C T L$ and $O H T$. (c) Difference (K) between (a) and (b) indicated by color contours. The solid and dotted gray lines indicate the tropopause level in $C T L$ and $O H T$, respectively, defined as the highest level at which the lapse rate falls to $2 \mathrm{~K} \mathrm{~km}^{-1}$ and computed according to the method of Reichler et al. (2003). Black contours are the $C T L$ zonal-mean air temperature $(\mathrm{K})$, with a contour interval of $10 \mathrm{~K}$ starting from $210 \mathrm{~K}$. (d), (e) Zonal-mean SST (K) for $C T L$ and $O H T$. (f) Difference (K) between (d) and (e). (g),(h) Zonal-mean zonal wind ( $\mathrm{m} \mathrm{s}^{-1}$ ) for CTL and $O H T$. (i) Difference (m s ${ }^{-1}$ ) between $(\mathrm{g})$ and $(\mathrm{h})$ indicated by color contours. Black contours indicate $C T L$ zonal-mean zonal wind, with a contour interval of $10 \mathrm{~m} \mathrm{~s}{ }^{-1}$. Unbroken contours indicate positive (westerly) values, dashed contours indicate negative (easterly) values, and the dotted line indicates the zero contour. (j),(k) Meridional overturning streamfunction $\left(\mathrm{kg} \mathrm{s}^{-1}\right)$ for $C T L$ and $O H T$. (l) Difference $\left(\mathrm{kg} \mathrm{s}^{-1}\right)$ between (j) and (k). Black contours indicate the $C T L$ streamfunction, with a contour interval of $1 \times 10^{10} \mathrm{~kg} \mathrm{~s}^{-1}$. Unbroken contours indicate positive (clockwise) values, dashed contours indicate negative (counterclockwise) values and the dotted line indicates the zero contour. (m),(n) Vertically averaged pressure velocity $\left(\mathrm{Pa} \mathrm{s}^{-1}\right)$ for $C T L$ and $O H T$. Note the reversed $y$ axis. (o) Difference $\left(\mathrm{Pa} \mathrm{s}^{-1}\right)$ between $(\mathrm{m})$ and $(\mathrm{n})$.

of the subtropical and midlatitude upper troposphere (Herweijer et al. 2005; Rose and Ferreira 2013) and to a reduction in global albedo associated with a decrease in subtropical low-cloud and equatorial convection when poleward OHT increases (Herweijer et al. 2005; Koll and Abbot 2013; Rencurrel and Rose 2018). Although $O H T$ causes SSTs to increase everywhere, this increase is not spatially uniform; the meridional SST gradient weakens in the tropics and subtropics and strengthens in middle and high latitudes (Fig. 2f), mirroring the spatial structure of the imposed $q$ flux.

Consequences of this global-mean warming include an increase in the tropospheric dry static stability from the tropics into high latitudes and an increase in the height of the tropopause globally (Fig. 2c). This static stability increase, which maximizes in the subtropics where the SST response is largest, is expected from the quasi-moist adiabatic adjustment of the tropical 
(Xu and Emanuel 1989) and midlatitude (Juckes 2000; Frierson 2008) troposphere to increasing boundary layer moist entropy. The increased tropopause height can be understood in terms of radiative constraints on the tropopause, coupled with the tropospheric moistening (increased optical thickness) and decreased lapse rates that occur as a consequence of the convective adjustment of the troposphere to increasing surface temperature (Thuburn and Craig 2000; Schneider 2007).

Next, the response of the annual-mean $\mathrm{HC}$ to $O H T$ is shown in Figs. $2 \mathrm{j}-1$ and in Table 2. Although changes to $\mathrm{HC}$ strength are not the focus of this paper, we note that $O H T$ causes an $O(20 \%)$ weakening of the HC compared to $C T L$, where $\mathrm{HC}$ strength is defined as the extremum of the streamfunction between $\phi_{i}$ and $\phi_{H}$. This comports with previous studies which find OHT weakens the $\mathrm{HC}$ by $20 \%-50 \%$ in the annual mean (Covey and Thompson 1989; Herweijer et al. 2005; Clement and Soden 2005; Clement 2006; Levine and Schneider 2011). Additionally, $O H T$ causes robust HC expansion; for a slab ocean depth of $12 \mathrm{~m}, O H T$ causes an annualmean poleward $\phi_{H}$ shift of $+3.06^{\circ}$. The total change in $\phi_{H}$ is sensitive to the depth of the slab ocean, with relatively shallow slab ocean simulations showing slightly less HC expansion than the 12-m case, and deeper slab ocean simulations showing substantially less HC expansion than the 12 -m case (Table 2). This poleward $\phi_{H}$ shift occurs in all seasons, although the annual-mean $\mathrm{HC}$ expansion is dominated by streamfunction anomalies that occur in the subtropics of the winter hemisphere (Fig. S1).

Finally, the climatological vertically averaged pressure velocity $\tilde{\omega}$ and its response to $O H T$ are shown in Figs. $2 \mathrm{~m}-\mathrm{O}$ for the annual mean. Note that the two upward velocity maxima in Figs. $2 \mathrm{~m}$ and $2 \mathrm{n}$ are not indicative of an instantaneous double ITCZ but are instead a feature of the annual averaging; as seen in Fig. S1, there is a single ITCZ during almost every calendar month for both $C T L$ and $O H T$. Compared to $C T L, O H T$ causes a broadening of the annual-mean ascending motion in the deep tropics. This annual-mean response is a signature of an increase in the amplitude of the seasonal cycle of ITCZ latitude (Table 2), which will be discussed at length in section 5, including its impact on $\mathrm{HC}$ extent.

\section{Theoretical framework: Baroclinicity and Hadley circulation extent}

In this section, we introduce and justify the theoretical framework that will be used to interpret the response of $\mathrm{HC}$ extent to OHT in our simulations. An axisymmetric thermally direct overturning circulation (e.g., Held and Hou 1980) cannot exist in Earth's atmosphere because the zonal winds implied by this angular-momentum-conserving flow are linearly baroclinically unstable. Thus, one theory for the width of the $\mathrm{HC}$ is that it is determined by the onset of significant baroclinic instability (Lorenz 1967; Held et al. 2000; Vallis et al. 2015). An analytical scaling for HC extent can be derived by matching the zonal wind profile implied by angular momentum conservation with the critical condition for baroclinic instability in the two-layer quasigeostrophic (Phillips 1954) model, and this scaling has been found to be accurate over a range of climates in both idealized (Frierson et al. 2007; Levine and Schneider 2015) and comprehensive (Frierson et al. 2007; Lu et al. 2007) atmospheric models. Such scaling theories have been criticized, however, for ignoring the important role that extratropical eddies play in driving the $\mathrm{HC}$ (Korty and Schneider 2008). To address this problem, several studies have generalized the theory to include the effects of midlatitude eddies on HC baroclinicity, and such studies have nevertheless indicated that baroclinicity is fundamental in limiting the poleward extent of the HC (Lu et al. 2008; Kang and Lu 2012; Tandon et al. 2013).

To determine if this theoretical framework is appropriate for our simulations, we examine the relationship between subtropical baroclinicity and the width of the $\mathrm{HC}$ for our ensemble of experiments. We quantify baroclinicity in terms of the Phillips criticality $C$ (Phillips 1954):

$$
C=\frac{f^{2}}{\beta g H} \frac{u_{500}-u_{850}}{\left(\theta_{500}-\theta_{850}\right) / \Theta},
$$

where, following $\mathrm{Lu}$ et al. (2008), $u$ is the zonal wind, $\theta$ is potential temperature, the subscripts 500 and 850 indicate the level (hPa) at which $u$ and $\theta$ are evaluated, $H$ is the thickness (m) of the $500-850-\mathrm{hPa}$ layer, $\Theta$ is the average potential temperature of the $500-850-\mathrm{hPa}$ layer, $f$ is the Coriolis parameter, and $\beta$ is the meridional gradient of $f$. Note that $C$-and baroclinicity more generally-increases with increasing wind shear $\left(u_{500}-u_{850}\right)$ and latitude (owing to the term $f^{2} / \beta$ ), and decreases with increasing dry static stability $\left(\theta_{500}-\theta_{850}\right)$ and vertical scale of the circulation $(H)$.

If the $\mathrm{HC}$ terminates where baroclinicity becomes sufficiently strong, one would expect the atmosphere to assume a near-constant value of $C$ at the HC edge. For our reference (12-m CTL) simulation, the value of $C$ at $\phi_{H}$ is 1.02 . We determine the latitude $\phi_{C_{\text {crit }}}$ at which this value of $C$ occurs for each experiment and scatter it against the simulated HC edge in Fig. 3a. With the exception of the 2.4-m experiments, $\phi_{C_{\text {crit }}}$ and $\phi_{H}$ correspond closely. This close correspondence is consistent with the theory introduced above that the $\mathrm{HC}$ extends poleward until it becomes significantly baroclinically unstable (i.e., until it 


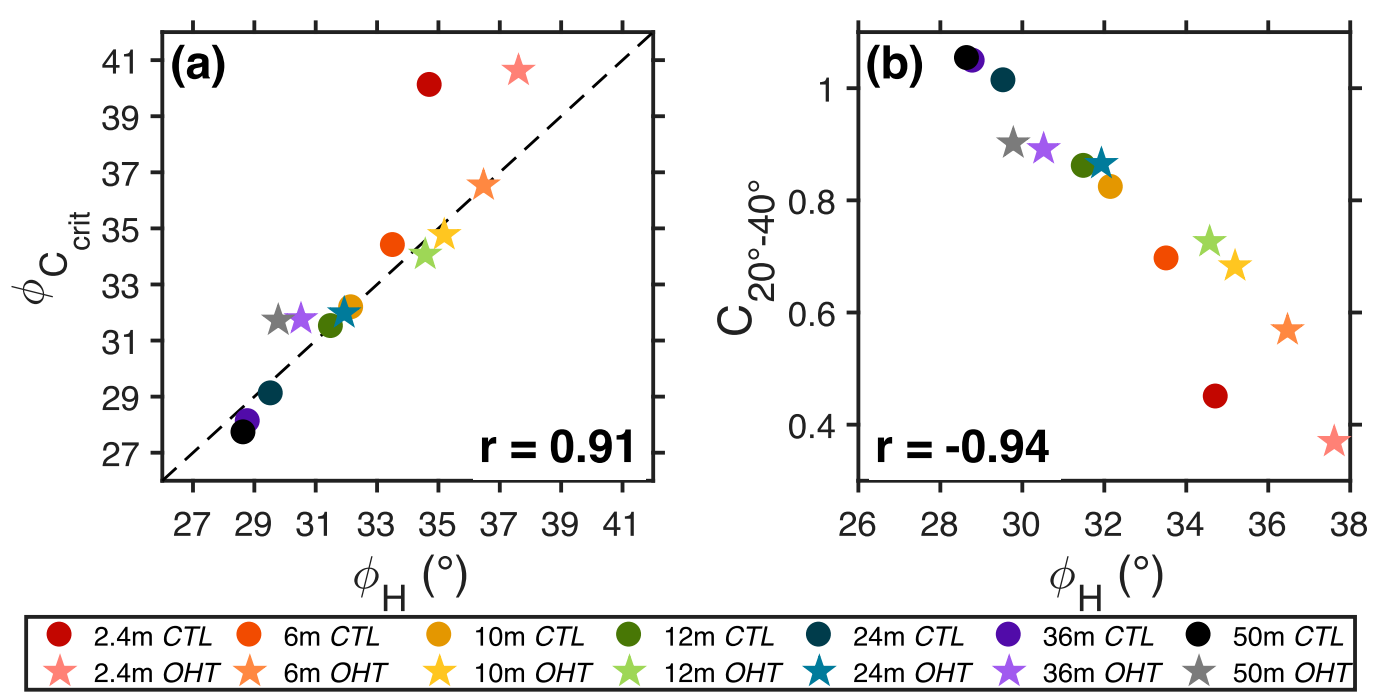

FIG. 3. (a) The latitude at which the Phillips criticality $C$ is equal to $C_{\text {crit }}$ vs $\phi_{H}$. Note that $C_{\text {crit }}=1.02$ is defined as the value of $C$ at $\phi_{H}$ in the 12-m $C T L$ experiment. For reference, the one-to-one line is shown in dashed black. (b) Phillips criticality $C$ area-averaged over $20^{\circ}-40^{\circ}$ latitude vs $\phi_{H}$. In (a) and (b), the correlation coefficient $r$ is also shown, with boldface type indicating statistical significance at the $95 \%$ confidence level according to a two-tailed $t$ test using Fisher's $Z$ transformation of the correlation coefficient. All values are annual-mean values.

reaches a critical value ${ }^{2}$ of $C$ ) and terminates. Additionally, the value of $C$ area-averaged over the subtropics $\left(20^{\circ}-40^{\circ}\right.$ latitude) is highly anticorrelated with $\phi_{H}$ (Fig. 3b), meaning that simulations with relatively low subtropical baroclinicity exhibit wider HCs than do simulations with relatively high subtropical baroclinicity, consistent with baroclinic control of $\mathrm{HC}$ extent.

That the HC adjusts to assume an approximately constant value of baroclinic criticality at its poleward boundary suggests that OHT causes the HC to expand by decreasing baroclinicity at the poleward boundary of the HC, allowing it to extend farther poleward. Thus, to understand how OHT causes the HC to expand, we must understand how OHT modifies subtropical baroclinicity. Next, we examine three pathways by which OHT modifies subtropical baroclinicity and the relative importance of each in driving $\mathrm{HC}$ expansion.

\section{Mechanisms for Hadley circulation widening in response to ocean heat transport}

\section{a. Increased subtropical static stability and tropopause height resulting from global-mean warming}

As discussed in section 3, OHT causes global-mean warming, which causes both an increase in subtropical

\footnotetext{
${ }^{2}$ For $C T L$ and $O H T$ experiments using slab ocean depths of 6 , $10,12,24,36$, and $50 \mathrm{~m}, C\left(\phi_{H}\right)$ ranges from 0.96 to 1.07 . The $2.4-\mathrm{m}$ $C T L$ and $O H T$ experiments are outliers, where $C\left(\phi_{H}\right)=0.67$ and 0.80 , respectively.
}

static stability and an increase in the vertical extent of the HC (i.e., an increase in tropopause height). These both imply a decrease in subtropical baroclinicity, and $\mathrm{HC}$ expansion is therefore predicted by the baroclinic instability theory of HC extent. Here we wish to separate the effect of global warming (and its associated impacts on subtropical static stability and tropopause height) from the other effects of OHT.

To achieve this separation, we perform a modified version of $O H T$ called $O H T+$ UniCool that preserves the meridional structure of the $O H T$ forcing but removes OHT's effect on global-mean temperature. The $q$ flux imposed in $\mathrm{OHT}+$ UniCool is

$$
Q_{\text {OHT+UniCool }}(\phi)=Q_{O H T}(\phi)+Q_{0},
$$

where $Q_{O H T}(\phi)$ is the $q$-flux profile from the $O H T$ experiment, and $Q_{0}=-3.61 \mathrm{Wm}^{-2}$ is a constant that has been calibrated such that the global-mean surface temperature is statistically identical in $C T L$ and OHT + UniCool (Tables 1 and 2).

The surface and air temperature responses to $O H T+$ UniCool are shown in Table 2 and Fig. 4. The change in $\overline{T_{s}}$ in $O H T+$ UniCool relative to $C T L$ is $-0.07 \mathrm{~K}$ (not statistically significant); thus, $O H T+$ UniCool eliminates the global-mean warming effect of OHT, as desired (Table 2, Fig. 4f). However, OHT+UniCool largely preserves the changes to the SST gradient that occurred in $O H T$ (cf. Fig. $4 \mathrm{f}$ and Fig. 2f). Finally, note that in the subtropics near the vicinity of the CTL HC 

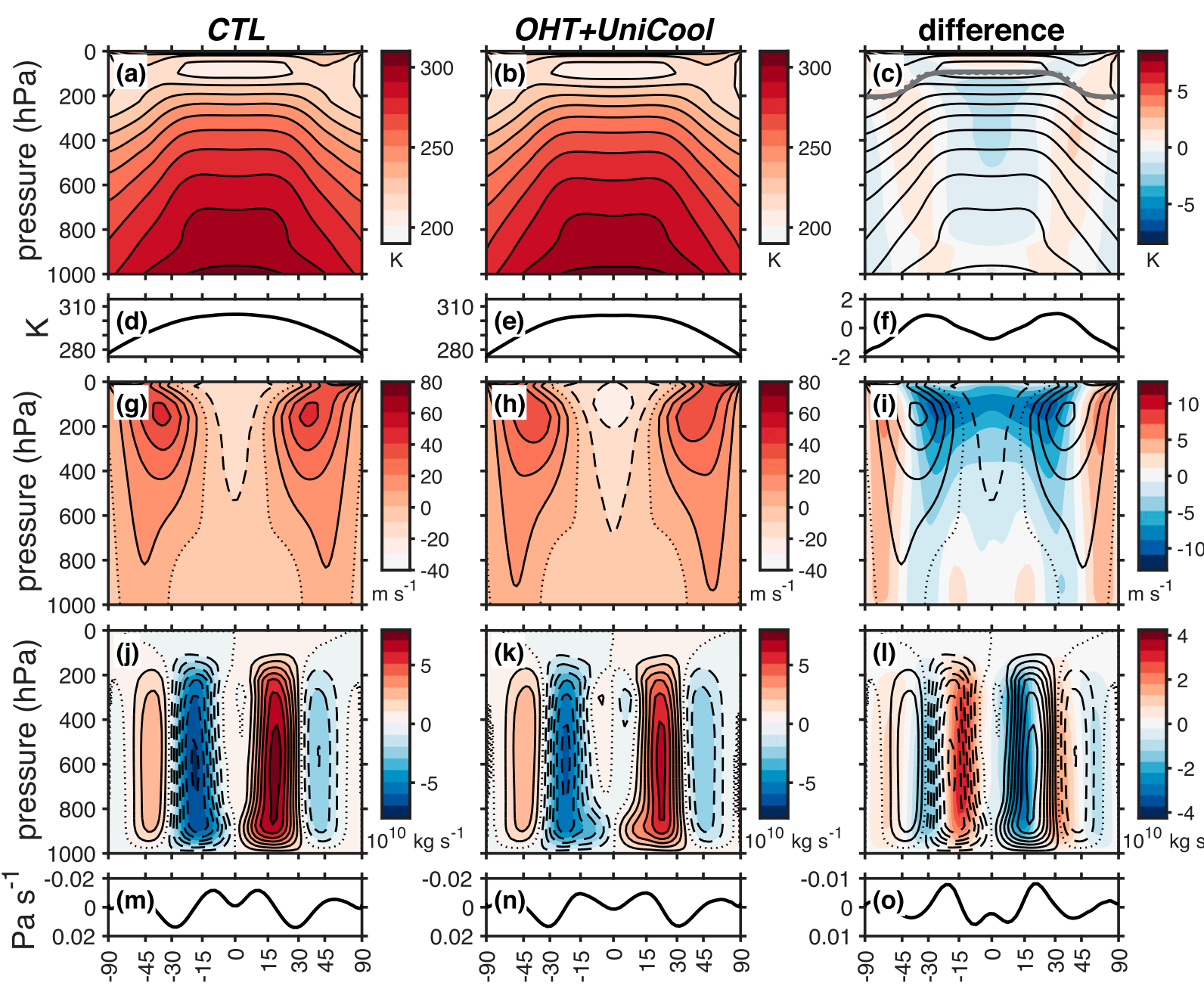

latitude $\left({ }^{\circ}\right)$
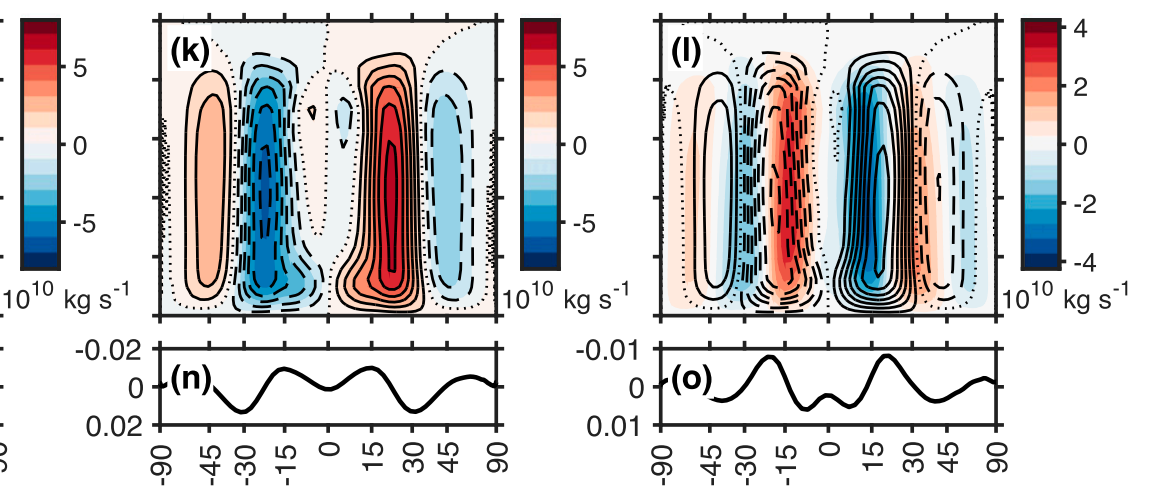

latitude $\left({ }^{\circ}\right)$

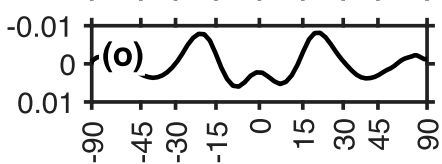

latitude $\left({ }^{\circ}\right)$

FIG. 4. As in Fig. 2, but for OHT+UniCool (slab ocean depth =12 m) instead of OHT.

edge $\left(31.51^{\circ}\right)$, there is virtually no change in subtropical static stability or tropopause height from $C T L$ to $O H T+U n i C o o l$, and thus any HC expansion that occurs in $\mathrm{OHT}+$ UniCool should not be due to an increase in subtropical static stability or tropopause height.

The response of the overturning circulation to $\mathrm{OHT}+$ UniCool is shown in Figs. $4 \mathrm{j}-\mathrm{O}$, and the response of $\phi_{H}$ is given in Table 2. At first glance, changes in the streamfunction and $\tilde{\omega}$ due to $\mathrm{OHT}+\mathrm{UniCool}$ are nearly indistinguishable from those changes due to $O H T$ (cf. Figs. 4j-o, Figs. 2j-o). As in OHT, OHT+UniCool causes a broadening of the annual-mean ITCZ and a weakening of the annual-mean $\mathrm{HC}$ (both responses are slightly stronger in $\mathrm{OHT}+$ UniCool than in $O H T$ ). The positive and negative streamfunction anomalies in the northern and southern subtropics, respectively, indicate that $O H T+U n i C o o l$ causes HC expansion; compared to $C T L, O H T+$ UniCool causes a shift in $\phi_{H}$ of $+2.31^{\circ}$
(Table 2). Recall that $O H T$ caused a $+3.06^{\circ}$ shift of $\phi_{H}$; thus, even though the global-mean warming (and the subsequent increase in subtropical static stability and tropopause height) is eliminated in $\mathrm{OHT}+$ UniCool, OHT + UniCool recovers over $75 \%$ of the HC's widening due to the full $O H T$ forcing!

These results suggest that the "global warming" effects of OHT are responsible for a relatively minor fraction $(\leq 25 \%)$ of the OHT-induced $\mathrm{HC}$ widening. A complimentary experiment in which only globally uniform heating (but no OHT) is imposed confirms this conclusion (see supplemental material). Thus, the meridional structure of the imposed OHT convergence and of the subsequent SST response is primarily responsible for the $\mathrm{HC}$ widening in response to OHT. To explain the remaining $75 \%$ of the OHT-induced $\mathrm{HC}$ widening, then, we must focus on $\mathrm{HC}$ expansion mechanisms that invoke the meridional structure of the OHT forcing. 


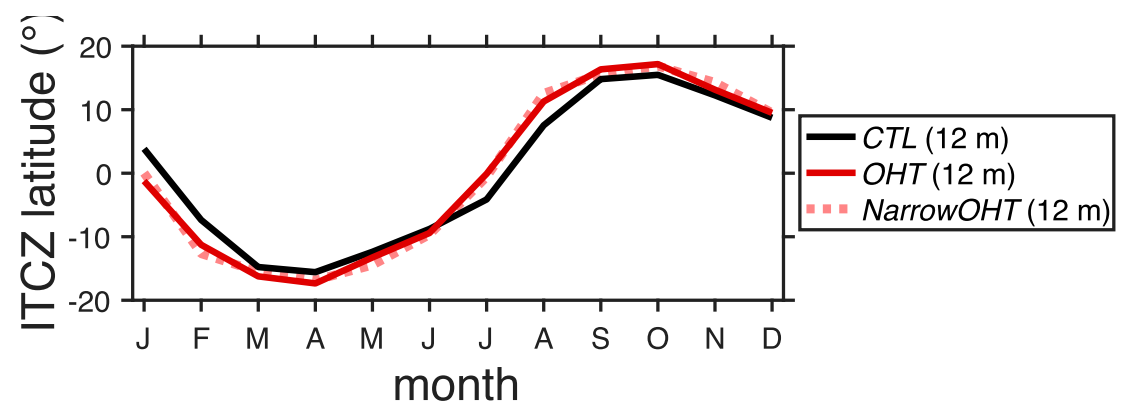

FIG. 5. Climatological ITCZ latitude as a function of calendar month for $C T L, O H T$, and NarrowOHT (NarrowOHT is described later in the paper in section 5b). Each simulation uses a slab ocean depth of $12 \mathrm{~m}$. The $x$ axis runs chronologically from January to December.

\section{b. Weakened wind shear driven by a systematic poleward shift of the ITCZ}

One consequence of the meridional structure of the imposed OHT convergence and of the subsequent SST response involves a change to the seasonal migration of the ITCZ. Compared to $C T L, O H T$ causes a systematic shift of the ITCZ away from the equator and into higher latitudes, that is, a broadening of the seasonal migration of the ITCZ (Fig. 5). This response is robust across slab ocean depth, although the magnitude of the change in the amplitude of the $\phi_{i}$ seasonal cycle depends on slab ocean depth (Table 2). The ITCZ response can be understood as follows: according to convective quasi-equilibrium theory, for $\mathrm{HCs}$ that are nearly angular momentum conserving [a reasonable approximation for the deep tropics (Bordoni and Schneider 2008; Schneider and Bordoni 2008)], the ITCZ is collocated with the maximum in near-surface moist static energy (MSE; Emanuel 1995; Privé and Plumb 2007). OHT cools equatorial SSTs relative to subtropical SSTs (Clement 2006), which allows the tropical near-surface MSE maximum in the warm hemisphere to move farther off the equator and farther into the warm hemisphere seasonally, and with it goes the ITCZ.

We hypothesize that these changes to ITCZ latitude contribute to the OHT-induced HC expansion as follows. The systematic poleward shift of the ITCZ during the annual cycle implies a decrease in the angular momentum of air parcels ventilated to the tropical upper troposphere, since atmospheric angular momentum per unit mass $m=(u+\Omega a \cos \phi) a \cos \phi$ decreases as latitude increases. Indeed, OHT causes decreases in tropical and globally integrated angular momentum that are consistent with this mechanism (see supplemental material). This reduction of tropical upper-tropospheric angular momentum implies a reduction in the zonal velocity throughout the upper branch of the $\mathrm{HC}$, which further implies a reduction in the vertical shear of the zonal wind throughout the $\mathrm{HC}$ since the near-surface winds are negligible compared to the winds aloft. This scenario is consistent with the OHT-induced zonal wind changes in Fig. 2i. Finally, this weakened wind shear implies a reduction in baroclinicity throughout the HC, and therefore $\mathrm{HC}$ expansion.

Thus, one way that OHT may cause the HC to expand is by systematically shifting the ITCZ into higher latitudes, reducing the angular momentum of the air ventilated to the $\mathrm{HC}$, and causing the onset of significant baroclinic instability to shift poleward (Fig. 6). Here, we attempt to establish how much (if any) of the OHT-induced HC expansion can be explained by this mechanism using two techniques: 1) a theoretical technique, in which we apply a simple scaling theory to predict the sensitivity of $\mathrm{HC}$ extent to variations in ITCZ latitude, and 2) an experimental technique, in which we run additional simulations that isolate these changes to ITCZ latitude and their subsequent impact on $\mathrm{HC}$ extent.

\section{1) SCALING ANALYSIS}

To better understand the role of the ITCZ in setting the mean width of the $\mathrm{HC}$ and its response to OHT, we analyze a modified version of the $\mathrm{HC}$ edge scaling derived by Kang and Lu (2012) [which is itself a modified version of an earlier scaling by Held et al. 2000]. According to the two-layer quasigeostrophic (Phillips 1954) model of baroclinic instability, the latitude at which a zonally symmetric $\mathrm{HC}$ would become baroclinically unstable is

$$
\phi_{H}=\left[\frac{1}{2}\left(\phi_{i}^{2}+\sqrt{\phi_{i}^{4}+\frac{2 g \Delta_{v} H_{0}}{\Omega^{2} a^{2}}}\right)\right]^{1 / 2},
$$

where $\Delta_{v}$ and $H_{0}$ are the gross dry stability and height of the circulation, respectively. Note that (6) is identical to 


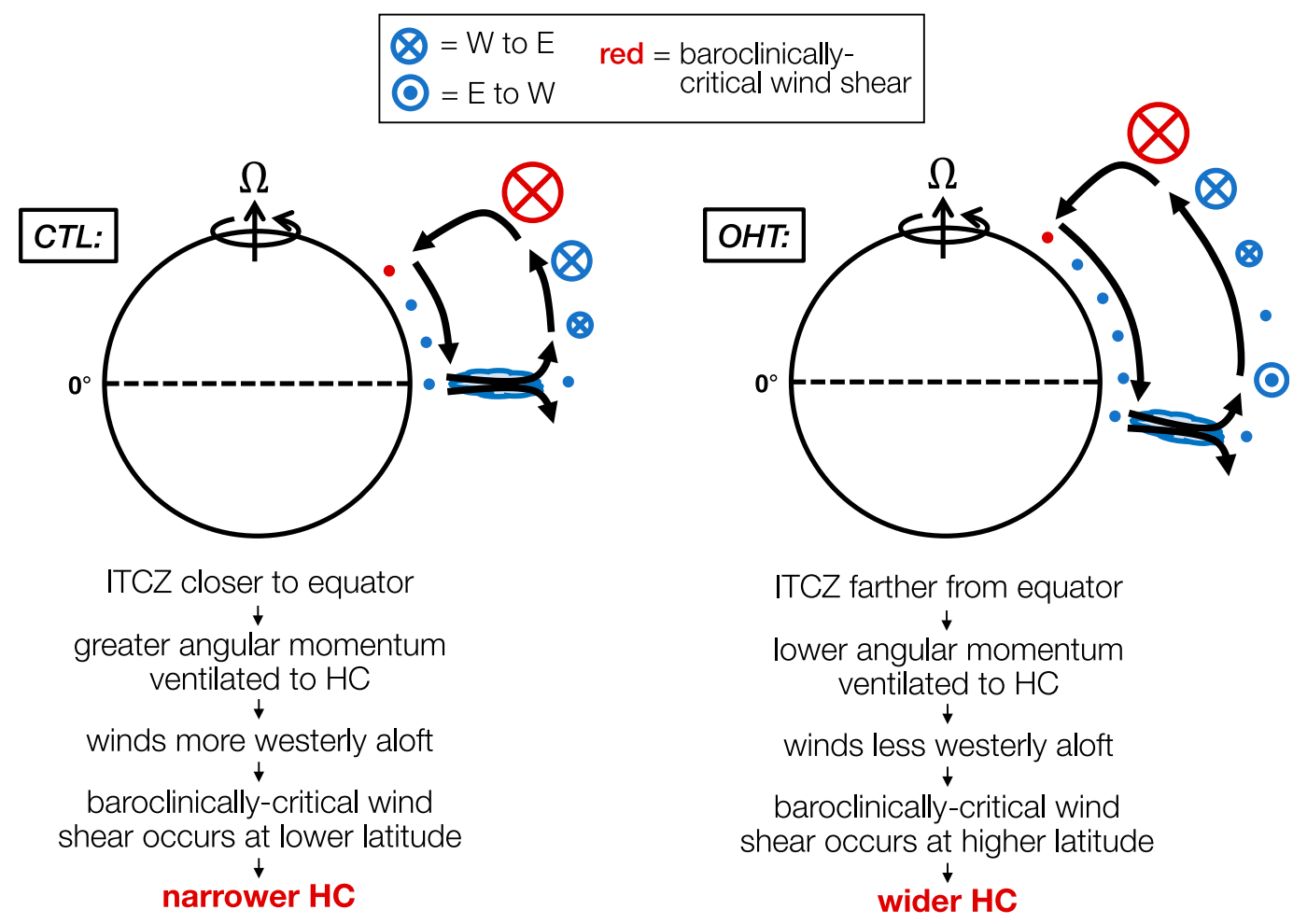

FIG. 6. Schematic depicting how OHT, by systematically shifting the ITCZ into higher latitudes, could cause a poleward shift of the poleward boundary of the Hadley circulation. Shown are schematics for (left) CTL and (right) $O H T$. Thinner black lines depict Earth (dashed line = equator) and its sense of rotation. Thick black arrows indicate the Hadley cells. The cartoon of a convective cloud represents the ITCZ. Blue vectors into and out of the page indicate westerlies and easterlies, respectively, with larger vectors indicating faster winds. Red vectors indicate winds that are baroclinically unstable.

(7) and (8) from Kang and $\mathrm{Lu}$ (2012), except here we consider the simplified case in which the local Rossby number Ro (which quantifies the proximity of the HC to its angular momentum-conserving limit) is equal to 1 . Similar to Kang and $\mathrm{Lu}(2012)$, the gross dry stability is calculated as $\Delta_{v}=\left(\theta_{2}-\theta_{1}\right) / 2 \Theta_{0}$, where $\theta_{2}$ and $\theta_{1}$ are the potential temperature at the tropopause and at $850 \mathrm{hPa}$, respectively, and $\Theta_{0}$ is the tropospheric mean temperature; $H_{0}$ is the thickness $(\mathrm{m})$ of the column between $850 \mathrm{hPa}$ and the tropopause; and the tropopause altitude is defined as the highest altitude at which the lapse rate falls to $2 \mathrm{~K} \mathrm{~km}^{-1}$, computed according to the method of Reichler et al. (2003). Both $\Delta_{v}$ and $H_{0}$ are area-averaged over a $20^{\circ}$ band centered on the $C T L \mathrm{HC}$ edge.

We begin by evaluating the scaled versus simulated $\phi_{H}$ for the $\mathrm{HC}$ in the winter ${ }^{3}$ hemisphere in Fig. 7a. Later, after its skill in predicting the climatological width

\footnotetext{
${ }^{3} \mathrm{We}$ define the winter $\mathrm{HC}$ as the cross-equatorial $\mathrm{HC}$ during the 3-month period during which the ITCZ is located farthest from the equator.
}

of the $\mathrm{HC}$ has been established, the scaling will be used to quantify the contribution of ITCZ shifts to the OHT-driven expansion of the winter HC (Fig. 8). We evaluate the scaling for the winter $\mathrm{HC}$ because changes to the winter $\mathrm{HC}$ dominate the annual-mean subtropical streamfunction changes (Fig. S1), and because although we expect the relationship between $\phi_{i}$ and $\phi_{H}$ to hold qualitatively throughout the year, (6) is likely most quantitatively accurate in winter when the $\mathrm{HC}$ is closest to its angular momentum-conserving limit (Bordoni and Schneider 2010; Kang and Lu 2012). Figure 7a indicates that despite the scaling theory's simplifying assumptions, it is reasonably skillful at predicting the simulated winter HC extent. The scaling has a slight tendency to over- and underpredict the winter $\phi_{H}$ in simulations with deep and shallow slab oceans, respectively, but most markers in Fig. 7a fall close to the one-to-one line. The 2.4-m simulations, for which the scaling underpredicts the simulated $\phi_{H}$ by $4^{\circ}-5^{\circ}$, are outliers.

To assess the role of the mean ITCZ position in setting the mean $\mathrm{HC}$ extent, the simulated winter-hemisphere $\phi_{H}$ is plotted as a function of $\phi_{i}$ in Fig. 7b. Here we have 
(a)

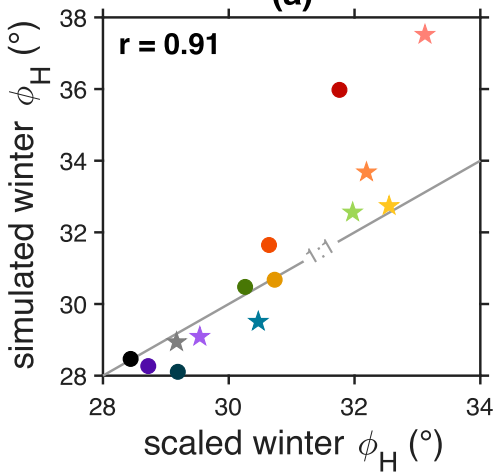

(b)

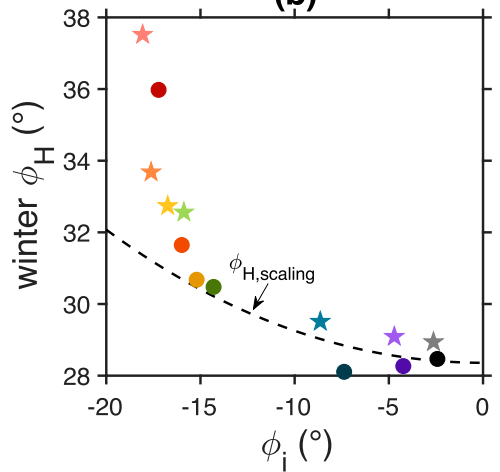

(c)

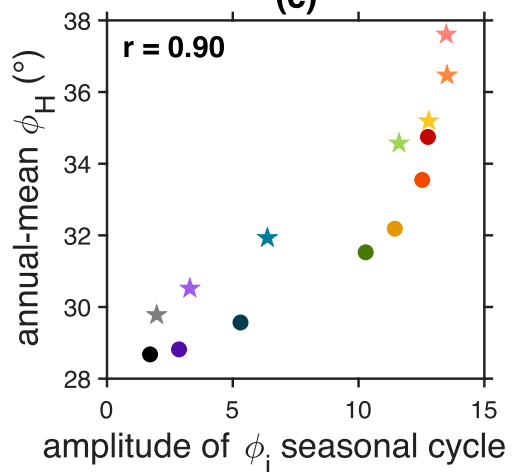

FIG. 7. (a) Simulated winter HC extent vs the winter HC extent that is expected from the scaling relationship given in (6). The one-toone line is plotted in gray for reference. (b) Markers show the simulated HC extent as a function of ITCZ latitude for the winter HC. The dashed black line shows the $\phi_{H}$ vs $\phi_{i}$ curve given by the scaling relationship in (6), where the $\Delta_{v}$ and $H_{0}$ used in the scaling are diagnosed from the winter $\mathrm{HC}$ of the $12-\mathrm{m} C T L$ experiment $\left(\Delta_{v}=0.16, H_{0}=16.0 \mathrm{~km}\right)$. (c) Simulated annual-mean HC extent as a function of the amplitude of the seasonal cycle of ITCZ latitude. In (a) and (c), a boldface $r$ value indicates that the correlation coefficient is statistically significant at the $95 \%$ confidence level according to a two-tailed $t$ test using Fisher's $Z$ transformation of the correlation coefficient.

used an ensemble of different slab ocean depths to exploit the fact that the ITCZ can move farther off the equator as the thermal inertia of the slab ocean decreases (Donohoe et al. 2014). Also shown in dashed black is the theoretical relationship between $\phi_{H}$ and $\phi_{i}$ given by (6) with $\Delta_{v}$ and $H_{0}$ fixed to their values from the reference (12-m CTL) simulation. Although in reality $\phi_{i}$ does not vary independently of $\Delta_{v}$ and $H_{0}$, fixing these values allows for a qualitative assessment of the importance of ITCZ latitude alone in setting the mean width of the HC. The scaling correctly predicts that ITCZs closer to the equator (i.e., ITCZs in simulations with deeper slab oceans) are associated with narrower HCs and that ITCZs farther from the equator (i.e.,
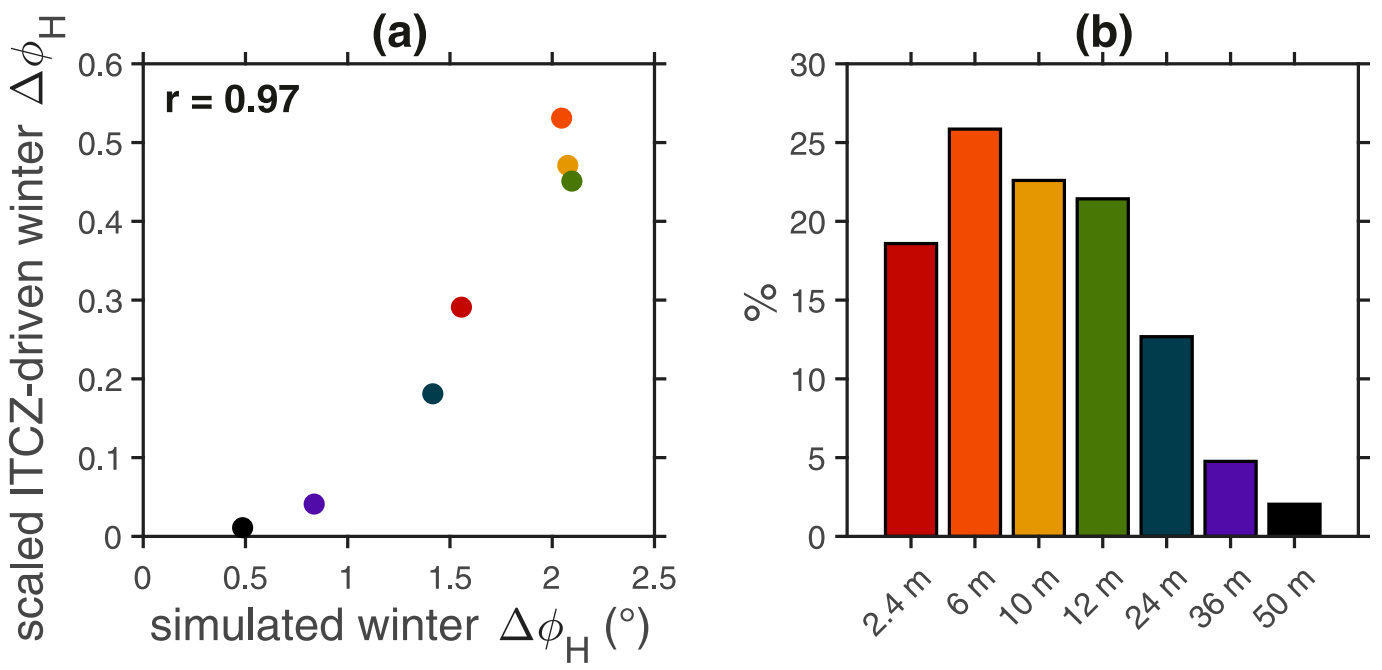

$2.4 \mathrm{~m} 6 \mathrm{~m} \bigcirc 10 \mathrm{~m} \bigcirc 12 \mathrm{~m} \bigcirc 24 \mathrm{~m} \odot 36 \mathrm{~m} \bigcirc 50 \mathrm{~m}$

FIG. 8. (a) The $y$ axis shows the change in winter $\phi_{H}$ that the scaling in (6) predicts would occur if only the ITCZ latitude changed from $C T L$ to $O H T$, with all other parameters remaining fixed at their $C T L$ values [e.g., (7)]. The $x$ axis shows the change in simulated winter $\phi_{H}$ from $C T L$ to $O H T$. (b) The percentage of the winter $\phi_{H}$ shift that, according to the scaling, can be attributed to the ITCZ shift [i.e. 100\% times the $y$ axis of (a) divided by the $x$ axis of (a)]. 
ITCZs in simulations with shallower slab oceans) are associated with wider HCs (Fig. 7b). Moreover, the scaling captures that $\mathrm{HC}$ extent is more sensitive to variations in ITCZ latitude as the ITCZ moves increasingly far from the equator.

Finally, we discuss qualitatively the role of the ITCZ in setting the annual-mean extent of the HC. Figure 7c shows the annual-mean $\mathrm{HC}$ extent as a function of $\Phi_{i}$, the amplitude of the seasonal cycle of ITCZ latitude given by (3). We consider $\Phi_{i}$ rather than the annualmean ITCZ latitude, because the annual-mean ITCZ latitude (which is $0^{\circ}$ for all of our simulations because of the hemispheric symmetry of the boundary conditions in the annual mean) does not capture the fact that the ITCZ can spend much of its time away from the equator during the seasonal cycle (Fig. 5), ventilating the tropical upper troposphere with air that has less angular momentum than that of air parcels at the annualmean ITCZ latitude. Additionally, using $\Phi_{i}$ rather than the annual-mean $\phi_{i}$ avoids complications associated with the annual-mean $\phi_{i}$ being located at a relative minimum in the annually-averaged upward velocity field, as occurs in some of our simulations as an artifact of the annual averaging (see discussion in section 3). As expected, simulations with greater $\Phi_{i}$ have wider annual-mean HCs $(r=0.90)$, consistent with the idea that ITCZs with larger seasonal migrations ventilate lower angular momentum air to the tropical upper troposphere on average, delaying the onset of baroclinic instability and moving the edge of the $\mathrm{HC}$ to higher latitudes.

We finish this analysis by using the scaling relationship to quantify the contribution of ITCZ shifts to the OHT-induced expansion of the HC. By (6), the estimated $\mathrm{HC}$ expansion that is driven by ITCZ shifts alone is

$$
\begin{aligned}
\left(\Delta \phi_{H}\right)_{\text {ITCZ-driven }} & \\
= & \left\{\frac{1}{2}\left[\left(\phi_{i}^{2}\right)_{O H T}+\sqrt{\left(\phi_{i}^{4}\right)_{O H T}+2 g\left(\Delta_{v} H_{0}\right)_{C T L} / \Omega^{2} a^{2}}\right]\right\}^{1 / 2} \\
& -\left\{\frac{1}{2}\left[\left(\phi_{i}^{2}\right)_{C T L}+\sqrt{\left(\phi_{i}^{4}\right)_{C T L}+2 g\left(\Delta_{v} H_{0}\right)_{C T L} / \Omega^{2} a^{2}}\right]\right\}^{1 / 2},
\end{aligned}
$$

where the "CTL" and "OHT" subscripts indicate quantities evaluated for $C T L$ and $O H T$, respectively. This quantity is plotted as a function of the total simulated HC expansion (again for the winter HC) in Fig. 8a. The scaling predicts that ITCZ shifts are responsible for $0.01^{\circ}-0.53^{\circ}$ of the OHT-induced HC expansion, depending on the depth of the slab ocean. For simulations with deep slab oceans and relatively narrow climatological ITCZ seasonal cycles, (7) predicts that ITCZ changes contribute very little to the total expansion of the HC. This is expected both because the ITCZ response to OHT is small when the slab ocean is deep (Table 2) and because the sensitivity of $\phi_{H}$ to changes in $\phi_{i}$ is small when $\phi_{i}$ is close to the equator (Fig. 7b). By contrast, for the reference $(12 \mathrm{~m})$ slab ocean depth, which produces a more realistic $\phi_{i}$ seasonal cycle, the scaling can explain nearly $0.5^{\circ}$ (or over $20 \%$; Fig. $8 \mathrm{~b}$ ) of the OHT-induced shift in wintertime $\phi_{H}$. The strong correlation between $\left(\Delta \phi_{H}\right)_{\text {ITCZ-driven }}$ and the total OHT-induced HC expansion $(r=0.97)$ suggests that this ITCZ-driven HC expansion mechanism is one reason why the total OHT-induced HC expansion is a function of slab ocean depth.

\section{2) MECHANISM-ISOLATION EXPERIMENT}

The prior scaling suggests that the poleward ITCZ shift explains $20 \%$ or more of the winter HC expansion in response to OHT (when the slab ocean depth is $12 \mathrm{~m}$ ). This heuristic scaling for HC extent may involve too many simplifications for it to be truly quantitative, however. Namely, the scaling assumes axisymmetric, angular-momentum-conserving flow ${ }^{4}$ in the HC's upper branch and a minimum wind shear for baroclinic instability, neither of which are strictly true for Earth's atmosphere (Schneider 2006; Zurita-Gotor and Lindzen 2007). As such, next we conduct a simulation that isolates OHT's effect on the ITCZ to more confidently assess the contribution of changes in ITCZ latitude to the response of HC width to OHT. This simulation will also allow for an assessment of the ITCZ's contribution to the annual-mean $\mathrm{HC}$ expansion, whereas previously we focused on its contribution during winter only.

We have argued that the systematic poleward shift of the ITCZ causes HC expansion by weakening the wind shear and thus decreasing the baroclinicity of the HC. We must therefore determine which of the OHTinduced wind shear changes in Fig. $2 \mathrm{i}$ are attributable to ITCZ changes alone. The key difficulty is that ITCZ latitude changes are likely not the only reason why OHT causes a reduction in wind shear throughout the $\mathrm{HC}$; namely, by cooling the deep tropics relative to the subtropics, OHT acts diabatically to weaken the meridional SST gradient across the HC. By thermal wind balance,

\footnotetext{
${ }^{4}$ The proximity of the $\mathrm{HC}$ to its angular momentum-conserving (AMC) limit can be quantified using the local Rossby number (Schneider and Bordoni 2008) Ro $=-\bar{\zeta} / f$, where $\zeta$ is the relative vorticity, with Ro $\rightarrow 1$ representing the AMC limit. For reference, among our different simulations Ro ranges from 0.43 to 0.59 in the winter-hemisphere $\mathrm{HC}$ and from near zero to 0.36 in the summerhemisphere $\mathrm{HC}$, where here we have averaged Ro over the upper branch of the $\mathrm{HC}$ from $\phi_{H}-15^{\circ}$ to $\phi_{H}$.
} 

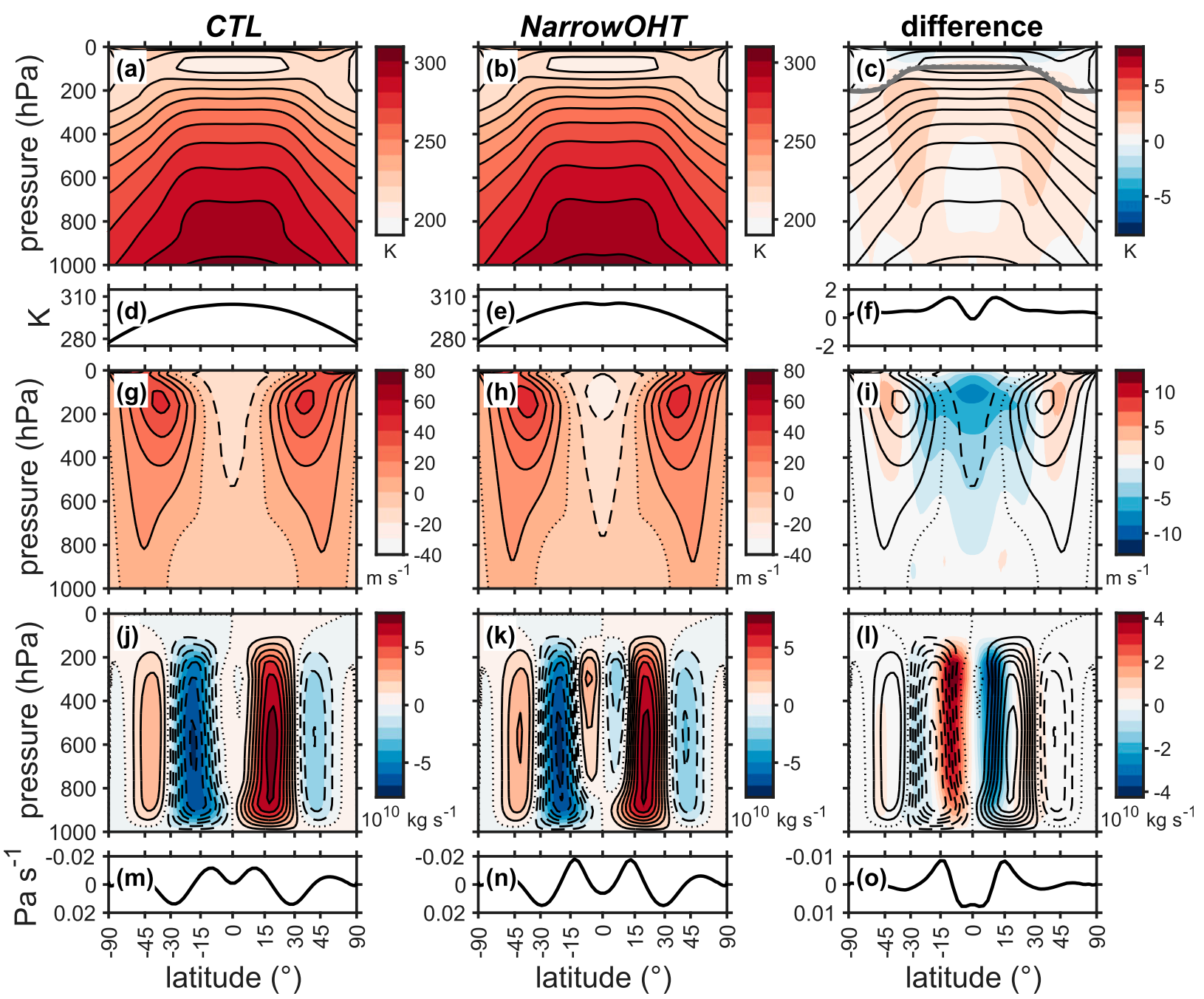

latitude $\left({ }^{\circ}\right)$

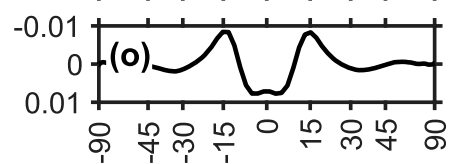

latitude $\left({ }^{\circ}\right)$

FIG. 9. As in Fig. 2, but for NarrowOHT (slab ocean depth $=12 \mathrm{~m}$ ) instead of $O H T$.

this implies a weakening of the vertical wind shear even in the absence of changes to ITCZ latitude.

To eliminate OHT's diabatic weakening of the subtropical SST gradient while preserving OHT's effect on the ITCZ, we shrink the meridional scale of the imposed OHT so that it is confined to a narrow region around the equator while leaving its peak value unchanged. This new experiment, called NarrowOHT, is described in Table 1 and Fig. 1. By cooling the equator and warming poleward of it, we expect Narrow $O H T$ to shift the ITCZ as $O H T$ did; however, the NarrowOHT $q$ flux tapers to zero by $25^{\circ}$ latitude so that Narrow $O H T$ no longer acts to weaken the SST gradient in the vicinity of the $C T L \mathrm{HC}$ edge $\left(31.51^{\circ}\right)$. If anything, the NarrowOHT $q$ flux should act to strengthen the meridional SST gradient between about $7.5^{\circ}$ and $25^{\circ}$ latitude; therefore, any $\mathrm{HC}$ expansion that occurs from $C T L$ to NarrowOHT should not be due to a weakening of the vertical wind shear associated with a weakening of the subtropical SST gradient.

The response of the seasonal cycle of ITCZ latitude to NarrowOHT is shown in Fig. 5. As desired, NarrowOHT causes the seasonal migration of the ITCZ to expand compared to $C T L$, and this expansion is nearly identical to that in the full $O H T$ experiment (see also Table 2). Next, the SST response to Narrow OHT is shown in Fig. 9. Note that NarrowOHT causes a strengthening of the SST gradient poleward of $\sim 10^{\circ}$ and that the SST response is virtually flat poleward of $\sim 25^{\circ}$ (Fig. 9f). Thus, Narrow OHT meets our objective: it preserves the ITCZ changes that occurred in the full $O H T$ experiment, while eliminating $O H T$ 's weakening of the subtropical SST gradient.

The response of the zonal-mean circulation to NarrowOHT is shown in Figs. 9g-o. NarrowOHT causes a weakening of the wind shear throughout the HC (Fig. 9i), consistent with the systematic increase 
in ITCZ latitude driving a decrease in HC angular momentum. The meridional temperature gradient in the free troposphere weakens (Fig. 9c) to adjust to these ITCZ latitude-driven changes to the momentum field as required by thermal wind balance. Narrow OHT causes positive and negative streamfunction anomalies in the northern and southern subtropics (Fig. 91), respectively, resulting in an annual-mean poleward shift of $\phi_{H}$ from CTL to NarrowOHT of $+0.85^{\circ}$, or $28 \%$ of the $+3.06^{\circ}$ shift that occurred from $C T L$ to $O H T$ (Table 2). Interestingly, NarrowOHT produces a bifurcation of the overturning circulation such that descending motion occurs on the equator in the annual mean (Fig. 9n), similar to the bifurcation that occurred in the simulations of Bischoff and Schneider (2016) as the amplitude of the prescribed OHT was increased, shifting the ITCZ away from the equator (and, like the present study, was accompanied by a widening $\mathrm{HC}$ ).

Since Narrow OHT reproduces $\sim 30 \%$ of the annualmean $\mathrm{HC}$ expansion that occurred in the full $O H T$ experiment, we conclude that $30 \%$ or more of the OHT-induced HC expansion can be attributed to changes in ITCZ latitude (at least for our reference slab ocean depth of $12 \mathrm{~m}$ ). Here, $30 \%$ is taken as a lower bound since the HC expansion that is driven by the ITCZ in NarrowOHT may be partially counteracted by the strengthened meridional SST gradient poleward of $10^{\circ}$. Finally, note that this $30 \%$ estimate is similar to the earlier estimate from the scaling analysis that ITCZ latitude changes cause $\gtrsim 20 \%$ of the $\mathrm{HC}$ widening in response to OHT.

\section{c. Diabatic weakening of the subtropical SST gradient}

We hypothesize that the remaining $\mathrm{HC}$ expansion can be attributed to a reduction in baroclinicity associated with OHT's diabatic relaxation of the subtropical meridional SST gradient. The previous NarrowOHT experiment gives an estimate of the importance of this mechanism; by eliminating the diabatic weakening of the subtropical SST gradient, NarrowOHT eliminated $72 \%$ of the widening that occurred in $O H T$, suggesting that OHT's diabatic relaxation of the subtropical meridional SST gradient could explain around $70 \%$ of the OHT-induced HC expansion. However, $70 \%$ is likely an overestimate, since NarrowOHT also eliminated most of the global-mean warming and its associated impacts on subtropical static stability and tropopause height (Fig. 9c). To address this issue, we run a variation on NarrowOHT in which the global-mean temperature increase is recovered. This new experiment, NarrowOHT+UniWarm, uses the same $q$ flux that was imposed in NarrowOHT with an additional superimposed globally uniform heating (Table 1 ) so that the global-mean surface temperatures in $O H T$ and NarrowOHT+UniWarm are statistically indistinguishable (Table 2).

The temperature and circulation responses to NarrowOHT+UniWarm are shown in Fig. 10. Note that the subtropical static stability and tropopause height increases in NarrowOHT+UniWarm are similar to those in $O H T$ (cf. Fig. 10c and Fig. 2c). Additionally, the seasonal migration of the ITCZ expands nearly as much in NarrowOHT+UniWarm as it did in OHT (Table 2). Meanwhile, the subtropical SST response in Narrow OHT + UniWarm is nearly flat (Fig. 10f), and so any HC expansion that occurs in NarrowOHT+UniWarm should be due to the combined effects of the increased ITCZ latitude and global-mean warming, not to a weakening of the subtropical SST gradient. Finally, the annual-mean change in $\phi_{H}$ that occurs from $C T L$ to NarrowOHT + UniWarm is $+1.31^{\circ}$, which is $43 \%$ of the full $O H T$ response (Table 2). This suggests that OHT's diabatic relaxation of the subtropical SST gradient is responsible for $55 \%-60 \%$ of the $\mathrm{HC}$ widening in response to OHT. One caveat is that since NarrowOHT+UniWarm acts to strengthen the meridional SST gradient between $10^{\circ}$ and $25^{\circ}$, the difference between NarrowOHT+UniWarm and $O H T$ cannot be strictly interpreted as the effect of removing OHT's weakening of the subtropical SST gradient. Thus, the difference between NarrowOHT+UniWarm and $O H T$ likely overstates the importance of OHT's weakening of the subtropical SST gradient in producing HC expansion, and our estimate that OHT's weakening of the subtropical SST gradient is responsible for $55 \%-60 \%$ of the HC expansion should be taken as an upper bound.

\section{Discussion and conclusions}

This study examines the impact of poleward ocean heat transport on the meridional extent of the Hadley circulation using a slab ocean aquaplanet model. It is found that a modern-day-like profile of OHT causes the $\mathrm{HC}$ to be wider than it would be in the absence of OHT. The total amount of HC expansion that occurs due to OHT is a function of the depth of the model's slab ocean; generally speaking, experiments with shallower slab oceans exhibit more $\mathrm{HC}$ expansion than do those experiments with deeper slab oceans (though the relationship between HC expansion and slab ocean depth is not monotonic; Table 2). For the choice of slab ocean depth $(12 \mathrm{~m})$ that produces a realistic annual-mean HC strength, meridional distribution of albedo and precipitation, and seasonal migration of the ITCZ, OHT causes a $3^{\circ}$ poleward shift of the $\mathrm{HC}$ edge.

$\mathrm{OHT}$ causes $\mathrm{HC}$ expansion by decreasing baroclinicity on the equatorward flank of the $\mathrm{HC}$ edge, allowing the $\mathrm{HC}$ 


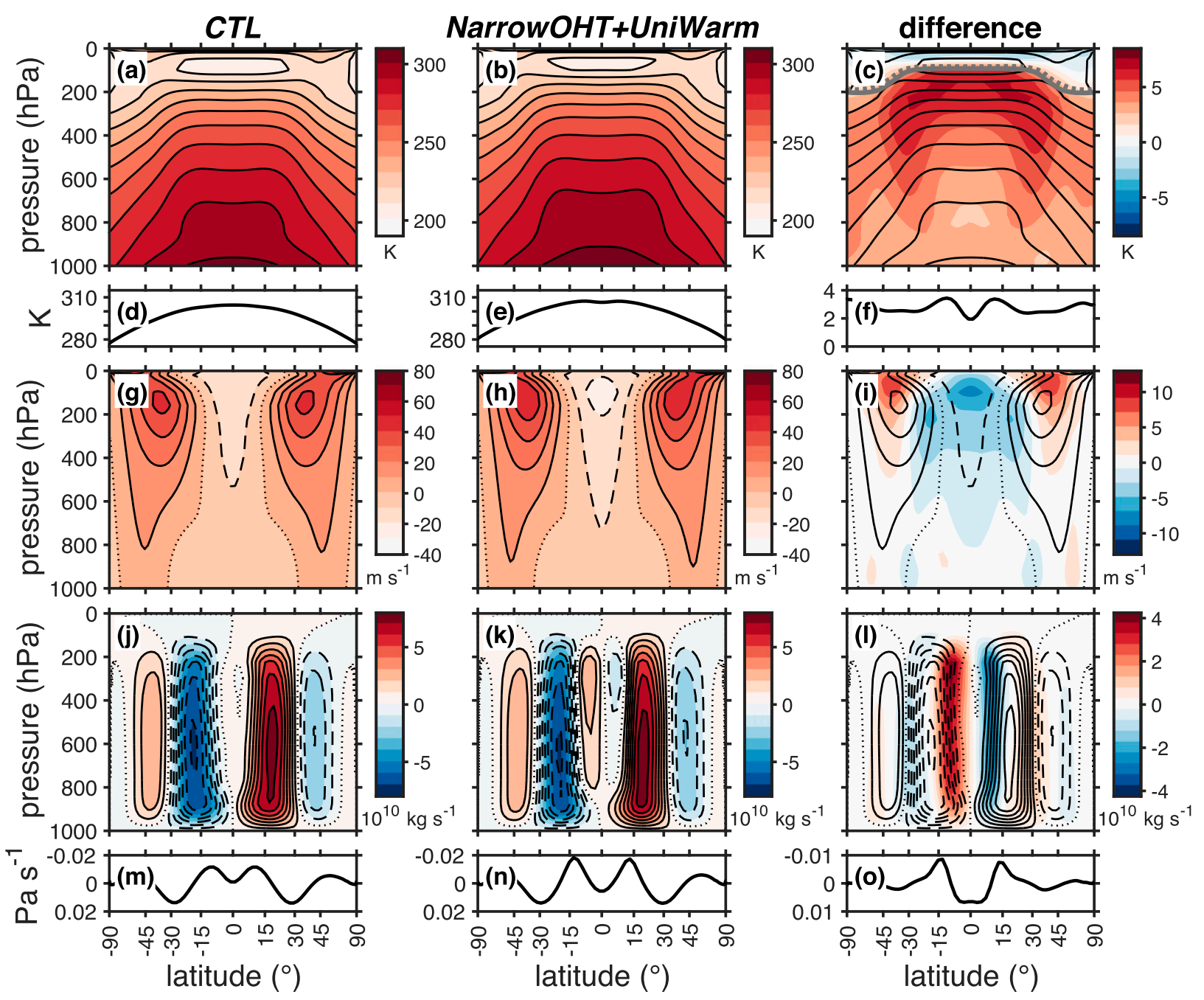

FIG. 10. As in Fig. 2, but for NarrowOHT+UniWarm (slab ocean depth $=12 \mathrm{~m}$ ) instead of $O H T$.

to extend farther poleward before becoming significantly baroclinically unstable. This decrease in baroclinicity is associated with three distinct mechanisms:

1) increased subtropical static stability and tropopause height resulting from the global-mean temperature increase caused by OHT,

2) decreased vertical wind shear resulting from a decrease in tropical upper-tropospheric angular momentum driven by an increase in the seasonal migration of the ITCZ, and

3) decreased wind shear resulting from the diabatic weakening of the subtropical meridional SST gradient by OHT.

For simulations with slab oceans of representative (12 m) depth, mechanism 3 contributes the most to the annual-mean $\mathrm{HC}$ expansion, explaining up to $55 \%-60 \%$ of the response of $\mathrm{HC}$ width to OHT. Mechanisms 1 and 2, however, are by no means negligible, and are estimated to account for around $20 \%-30 \%$ and $25 \%$ of the response of HC width to OHT, respectively.

A few comments regarding this partitioning are in order. First, we caution that these experiments have been performed using only one atmospheric model, the GFDL AM2.1. Second, this partitioning is likely sensitive to the effective heat capacity of the slab ocean (e.g., Fig. 8b), underscoring the importance of an appropriate choice of slab ocean depth in aquaplanet simulations as previously emphasized by Donohoe et al. (2014). Relatedly, we speculate that the nonmonotonic behavior of the total OHT-induced HC expansion with slab ocean depth may derive from the nonmonotonic behavior of the global-mean temperature and ITCZ responses with slab ocean depth (Table 2), though further mechanismdenial simulations with different slab ocean depths are required to confirm this hypothesis. 
In this study, we have focused on tropical sources of $\mathrm{HC}$ expansion since the imposed forcing by OHT is largest in the tropics. It is known, however, that eddy fluxes of heat and momentum from midlatitude baroclinic eddies affect the width of the HC (Schneider 2006; Walker and Schneider 2006). For example, it has been shown that increases in midlatitude eddy phase speeds can drive HC expansion by shifting poleward the latitude at which the eddies break in the subtropics $(\mathrm{Lu}$ et al. 2008; Ceppi and Hartmann 2013). To determine whether such a mechanism could be causing $\mathrm{HC}$ expansion in our simulations, we have computed latitudephase speed spectra of annual upper-tropospheric eddy momentum flux but find no evidence of an eddy phase speed shift (Fig. S4). A second possibility is that the OHT-induced weakening of the upper-level westerlies in the subtropics (Fig. 2i), which we argue is driven by a combination of an increase in the seasonal migration of the ITCZ and of OHT's relaxation of the subtropical SST gradient, could draw subtropical wave breaking poleward and induce a poleward shift of the HC edge. Such a scenario-which resembles the response of HC width to La Niña as discussed by Seager et al. (2003), Lu et al. (2008), and Ceppi and Hartmann (2013)—could represent an important positive feedback on the response of $\mathrm{HC}$ width to OHT due to mechanisms 2 and 3 above. Indeed, Fig. S4 indicates that eddy momentum fluxes and subtropical wave breaking shift poleward when OHT is imposed, consistent with this scenario; however, without additional experiments that can separate the mean and eddy-mediated responses of the $\mathrm{HC}$ to OHT, it is difficult to determine how large of a feedback this might be. Relatedly, the HC edge and eddy-driven jet (EDJ) are coupled-at least during some seasons and in some hemispheres-and many studies note that the two often shift in tandem (Kang and Polvani 2011; Kidston et al. 2013; Mbengue and Schneider 2013; Staten and Reichler 2014). For example, Ceppi and Hartmann (2016) found that cloud feedbacks that strengthen the extratropical heating gradient cause both the EDJ and the HC to shift poleward. OHT causes a poleward shift of the EDJ in our simulations (Fig. 2i), and so it is possible that part of the OHT-induced HC expansion is a response to this poleward EDJ shift. [It is also possible that the $\mathrm{HC}$ expansion forces the poleward EDJ shift (e.g., Mbengue and Schneider 2018).] On the other hand, we note that the annual-mean HC expansion is dominated by changes to the winter $\mathrm{HC}$ (Fig. S1), and the relationship between $\mathrm{HC}$ extent and the EDJ tends to be weak in winter (Kang and Polvani 2011; Hendon et al. 2014; Nguyen et al. 2018).

The results shown here emphasize the role of the ITCZ in setting the climatological width of the $\mathrm{HC}$ and its response to external forcing. Although we are not the first to explore such a link between ITCZ latitude and $\mathrm{HC}$ extent [see Kang and $\mathrm{Lu}$ (2012) and Staten and Reichler (2014) for discussions of this mechanism in the context of global warming and interannual $\mathrm{HC}$ variability, respectively], to our knowledge, ours are the first simulations to go beyond a diagnostic relationship between HC extent and ITCZ latitude by isolating this mechanism experimentally. Moreover, we have explored this mechanism in the context of a new forcingpoleward OHT_for which the mechanism appears to be particularly important. More broadly, these results elucidate the role of the seasonal cycle of ITCZ latitude in setting the mean width of the HC; namely, simulations with narrow ITCZ seasonal cycles (i.e., deep slab oceans) have narrower climatological HCs than simulations with wide ITCZ seasonal cycles (i.e., shallow slab oceans). An important implication is that simulations using annualmean insolation or overly deep or shallow slab oceans will, by virtue of having unrealistic ITCZ climatologies, likely produce climatological HCs that are too narrow or too wide.

That variations in ITCZ latitude can drive HC expansion or contraction by modifying subtropical baroclinicity has been under appreciated. We hope the results presented here will encourage others to consider the role of ITCZ latitude in modulating the response of $\mathrm{HC}$ extent to external forcing. For example, during El Niño events, the ITCZ shifts equatorward, atmospheric angular momentum increases, and the $\mathrm{HC}$ contracts (Adames and Wallace 2017); although this HC contraction is typically attributed to changes in eddy propagation due to a thermally-driven strengthening of the subtropical jet (Seager et al. 2003), these changes to ITCZ latitude, atmospheric angular momentum, and $\mathrm{HC}$ extent are also consistent with the mechanism outlined here. It would be interesting to reexamine the HC response to El Niño in light of these results and quantify how much (if any) of the HC contraction can be explained by an equatorward shift of the ITCZ and subsequent increase in subtropical baroclinicity. Relatedly, we note that the SST trend in recent decades has been "La Niña-like" in the equatorial Pacific, and that climate models forced with observed concentrations of greenhouse gases, aerosols, and ozone-which typically do not reproduce this recent La Niña-like trend, at least in the multimodel mean - tend to underestimate the rate of recent $\mathrm{HC}$ expansion by up to an order of magnitude (Kohyama et al. 2017; Allen and Kovilakam 2017; Davis and Birner 2017). Our results suggest that part of the Hadley cell expansion over the past 30 years could be related to the trend toward more La Niña-like states during the same period. 
Acknowledgments. The authors gratefully acknowledge three anonymous reviewers for their constructive feedback. CCH and DLH acknowledge support from the National Science Foundation (Grant AGS-1549579). $\mathrm{CCH}$ was supported by the National Defense Science and Engineering Graduate Fellowship Program, the Achievement Rewards for College Scientists Foundation, and an American Meteorological Society Graduate Fellowship.

\section{REFERENCES}

Adam, O., T. Schneider, and N. Harnik, 2014: Role of changes in mean temperatures versus temperature gradients in the recent widening of the Hadley circulation. J. Climate, 27, 7450-7461, https://doi.org/10.1175/JCLI-D-14-00140.1.

— T. Bischoff, and T. Schneider, 2016: Seasonal and interannual variations of the energy flux equator and ITCZ. Part I: Zonally averaged ITCZ position. J. Climate, 29, 3219-3230, https:// doi.org/10.1175/JCLI-D-15-0512.1.

Adames, Á. F., and J. M. Wallace, 2017: On the tropical atmospheric signature of El Niño. J. Atmos. Sci., 74, 1923-1939, https://doi.org/10.1175/JAS-D-16-0309.1.

Allen, R. J., and M. Kovilakam, 2017: The role of natural climate variability in recent tropical expansion. J. Climate, 30, 63296350, https://doi.org/10.1175/JCLI-D-16-0735.1.

Anderson, J. L., and Coauthors, 2004: The new GFDL global atmosphere and land model AM2-LM2: Evaluation with prescribed SST simulations. J. Climate, 17, 4641-4673, https:// doi.org/10.1175/JCLI-3223.1.

Bischoff, T., and T. Schneider, 2016: The equatorial energy balance, ITCZ position, and double-ITCZ bifurcations. J. Climate, 29, 2997-3013, https://doi.org/10.1175/JCLI-D-15-0328.1.

Bordoni, S., and T. Schneider, 2008: Monsoons as eddy-mediated regime transitions of the tropical overturning circulation. Nat. Geosci., 1, 515-519, https://doi.org/10.1038/ngeo248.

- , and -2010 : Regime transitions of steady and timedependent Hadley circulations: Comparison of axisymmetric and eddy-permitting simulations. J. Atmos. Sci., 67, 1643 1654, https://doi.org/10.1175/2009JAS3294.1.

Bretherton, C. S., M. Widmann, V. P. Dymnikov, J. M. Wallace, and I. Bladé, 1999: The effective number of spatial degrees of freedom of a time-varying Field. J. Climate, 12, 1990-2009, https://doi.org/10.1175/1520-0442(1999)012<1990: TENOSD $>2.0 . \mathrm{CO} ; 2$.

Butler, A. H., D. W. J. Thompson, and R. Heikes, 2010: The steadystate atmospheric circulation response to climate change-like thermal forcings in a simple general circulation model. J. Climate, 23, 3474-3496, https://doi.org/10.1175/2010JCLI3228.1.

Ceppi, P., and D. L. Hartmann, 2013: On the speed of the eddydriven jet and the width of the Hadley cell in the Southern Hemisphere. J. Climate, 26, 3450-3465, https://doi.org/10.1175/ JCLI-D-12-00414.1.

$\longrightarrow$, and - 2016: Clouds and the atmospheric circulation response to warming. J. Climate, 29, 783-799, https://doi.org/ 10.1175/JCLI-D-15-0394.1.

Clement, A. C., 2006: The role of the ocean in the seasonal cycle of the Hadley circulation. J. Atmos. Sci., 63, 3351-3365, https:// doi.org/10.1175/JAS3811.1.

- and B. Soden, 2005: The sensitivity of the tropical-mean radiation budget. J. Climate, 18, 3189-3203, https://doi.org/ 10.1175/JCLI3456.1.
Covey, C., and S. Thompson, 1989: Testing the effects of ocean heat transport on climate. Palaeogeogr. Palaeoclimatol. Palaeoecol., 75, 331-341, https://doi.org/10.1016/0031-0182(89)90193-4.

D'Agostino, R., P. Lionello, O. Adam, and T. Schneider, 2017: Factors controlling Hadley circulation changes from the Last Glacial Maximum to the end of the 21st century. Geophys. Res. Lett., 44, 8585-8591, https://doi.org/10.1002/ 2017GL074533.

Davis, N. A., and T. Birner, 2017: On the discrepancies in tropical belt expansion between reanalyses and climate models and among tropical belt width metrics. J. Climate, 30, 1211-1231, https://doi.org/10.1175/JCLI-D-16-0371.1.

— D. J. Seidel, T. Birner, S. M. Davis, and S. Tilmes, 2016: Changes in the width of the tropical belt due to simple radiative forcing changes in the GeoMIP simulations. Atmos. Chem. Phys., 16, $10083-10095$, https://doi.org/10.5194/ acp-16-10083-2016.

Donohoe, A., D. M. W. Frierson, and D. S. Battisti, 2014: The effect of ocean mixed layer depth on climate in slab ocean aquaplanet experiments. Climate Dyn., 43, 1041-1055, https:// doi.org/10.1007/s00382-013-1843-4.

Eady, E. T., 1949: Long waves and cyclone waves. Tellus, 1 (3), 3352, https://doi.org/10.3402/tellusa.v1i3.8507.

Emanuel, K. A., 1995: On thermally direct circulations in moist atmospheres. J. Atmos. Sci., 52, 1529-1534, https://doi.org/ 10.1175/1520-0469(1995)052<1529:OTDCIM > 2.0.CO;2.

Frierson, D. M. W., 2008: Midlatitude static stability in simple and comprehensive general circulation models. J. Atmos. Sci., 65, 1049-1062, https://doi.org/10.1175/2007JAS2373.1.

— , and Y. T. Hwang, 2012: Extratropical influence on ITCZ shifts in slab ocean simulations of global warming. J. Climate, 25, 720-733, https://doi.org/10.1175/JCLI-D-11-00116.1.

, J. Lu, and G. Chen, 2007: Width of the Hadley cell in simple and comprehensive general circulation models. Geophys. Res. Lett., 34, L18804, https://doi.org/10.1029/2007GL031115.

Held, I. M., and A. Y. Hou, 1980: Nonlinear axially symmetric circulations in a nearly inviscid atmosphere. J. Atmos. Sci., 37, 515-533, https://doi.org/10.1175/1520-0469(1980)037<0515: NASCIA $>2.0 . \mathrm{CO} ; 2$.

— , and Coauthors, 2000: The general circulation of the atmosphere. Woods Hole Oceanographic Institution, 54 pp., http:// www. whoi.edu/fileserver.do? $\mathrm{id}=21464 \& \mathrm{pt}=10 \& \mathrm{p}=17332$.

Hendon, H. H., E. P. Lim, and H. Nguyen, 2014: Seasonal variations of subtropical precipitation associated with the southern annular mode. J. Climate, 27, 3446-3460, https://doi.org/ 10.1175/JCLI-D-13-00550.1.

Herweijer, C., R. Seager, M. Winton, and A. Clement, 2005: Why ocean heat transport warms the global mean climate. Tellus, 57A, 662-675, https://doi.org/10.3402/tellusa.v57i4.14708.

Juckes, M. N., 2000: The static stability of the midlatitude troposphere: The relevance of moisture. J. Atmos. Sci., 57, 3050-3057, https://doi.org/10.1175/1520-0469(2000)057<3050: TSSOTM $>2.0 . \mathrm{CO} ; 2$.

Kang, S. M., and L. M. Polvani, 2011: The interannual relationship between the latitude of the eddy-driven jet and the edge of the Hadley cell. J. Climate, 24, 563-568, https://doi.org/10.1175/ 2010JCLI4077.1.

, and J. Lu, 2012: Expansion of the Hadley cell under global warming: Winter versus summer. J. Climate, 25, 8387-8393, https://doi.org/10.1175/JCLI-D-12-00323.1.

Kidston, J., C. W. Cairns, and P. Paga, 2013: Variability in the width of the tropics and the annular modes. Geophys. Res. Lett., 40, 2328-2332, https://doi.org/10.1029/2012GL054165. 
Knietzsch, M.-A., A. Schroder, V. Lucarini, and F. Lunkeit, 2015: The impact of oceanic heat transport on the atmospheric circulation. Earth Syst. Dyn., 6, 591-615, https://doi.org/10.5194/ esd-6-591-2015.

Kohyama, T., D. L. Hartmann, and D. S. Battisti, 2017: La Niñalike mean-state response to global warming and potential oceanic roles. J. Climate, 30, 4207-4225, https://doi.org/10.1175/ JCLI-D-16-0441.1.

Koll, D. D. B., and D. S. Abbot, 2013: Why tropical sea surface temperature is insensitive to ocean heat transport changes. J. Climate, 26, 6742-6749, https://doi.org/10.1175/JCLI-D-13-00192.1.

Korty, R. L., and T. Schneider, 2008: Extent of Hadley circulations in dry atmospheres. Geophys. Res. Lett., 35, L23803, https:// doi.org/10.1029/2008GL035847.

Levine, X. J., and T. Schneider, 2011: Response of the Hadley circulation to climate change in an aquaplanet GCM coupled to a simple representation of ocean heat transport. J. Atmos. Sci., 68, 769-783, https://doi.org/10.1175/2010JAS3553.1.

— , and - 2015: Baroclinic eddies and the extent of the Hadley circulation: An idealized GCM study. J. Atmos. Sci., 72, 2744-2760, https://doi.org/10.1175/JAS-D-14-0152.1.

Lorenz, E. N., 1967: The Nature and Theory of the General Circulation of the Atmosphere. World Meteorological Organization, $161 \mathrm{pp}$.

Lu, J., G. A. Vecchi, and T. Reichler, 2007: Expansion of the Hadley cell under global warming. Geophys. Res. Lett., 34, L06805, https://doi.org/10.1029/2006GL028443.

—, G. Chen, and D. M. W. Frierson, 2008: Response of the zonal mean atmospheric circulation to El Niño versus global warming. J. Climate, 21, 5835-5851, https://doi.org/10.1175/ 2008JCLI2200.1.

Mantsis, D. F., B. R. Lintner, A. J. Broccoli, M. P. Erb, A. C. Clement, and H. S. Park, 2014: The response of large-scale circulation to obliquity-induced changes in meridional heating gradients. J. Climate, 27, 5504-5516, https://doi.org/10.1175/ JCLI-D-13-00526.1.

Mbengue, C., and T. Schneider, 2013: Storm track shifts under climate change: What can be learned from large-scale dry dynamics. J. Climate, 26, 9923-9930, https://doi.org/10.1175/ JCLI-D-13-00404.1.

$\longrightarrow$, and — 2018: Linking Hadley circulation and storm tracks in a conceptual model of the atmospheric energy balance. J. Atmos. Sci., 75, 841-856, https://doi.org/10.1175/JAS-D-17-0098.1.

Nguyen, H., H. H. Hendon, E. P. Lim, G. Boschat, E. Maloney, and B. Timbal, 2018: Variability of the extent of the Hadley circulation in the Southern Hemisphere: A regional perspective. Climate Dyn., 50, 129-142, https://doi.org/10.1007/ s00382-017-3592-2.

Phillips, N. A., 1954: Energy transformations and meridional circulations associated with simple baroclinic waves in a twolevel, quasi-geostrophic model. Tellus, 6, 274-286, https://doi.org/ 10.3402/tellusa.v6i3.8734.

Privé, N. C., and R. A. Plumb, 2007: Monsoon dynamics with interactive forcing. Part I: Axisymmetric studies. J. Atmos. Sci., 64, 1417-1430, https://doi.org/10.1175/JAS3916.1.

Reichler, T., M. Dameris, and R. Sausen, 2003: Determining the tropopause height from gridded data. Geophys. Res. Lett., 30, 2042, https://doi.org/10.1029/2003GL018240.

Rencurrel, M. C., and B. E. J. Rose, 2018: Exploring the climatic response to wide variations in ocean heat transport on an aquaplanet. J. Climate, 31, 6299-6318, https://doi.org/10.1175/ JCLI-D-17-0856.1.
Rose, B. E. J., and D. Ferreira, 2013: Ocean heat transport and water vapor greenhouse in a warm equable climate: A new look at the low gradient paradox. J. Climate, 26, 2117-2136, https://doi.org/10.1175/JCLI-D-11-00547.1.

Schneider, T., 2006: The general circulation of the atmosphere. Annu. Rev. Earth Planet. Sci., 34, 655-688, https://doi.org/ 10.1146/annurev.earth.34.031405.125144.

_- 2007: The thermal stratification of the extratropical atmosphere. The Global Circulation of the Atmosphere, T. Schneider and A. H. Sobel, Eds., Princeton University Press, 47-77.

_ the seasonal cycle of a Hadley circulation and implications for monsoon dynamics. J. Atmos. Sci., 65, 915-934, https://doi.org/ 10.1175/2007JAS2415.1.

Seager, R., N. Harnik, Y. Kushnir, W. A. Robinson, and J. Miller, 2003: Mechanisms of hemispherically symmetric climate variability. J. Climate, 16, 2960-2978, https://doi.org/10.1175/ 1520-0442(2003)016<2960:MOHSCV > 2.0.CO;2.

Shaw, T. A., and A. Voigt, 2016: What can moist thermodynamics tell us about circulation shifts in response to uniform warming? Geophys. Res. Lett., 43, 4566-4575, https://doi.org/10.1002/ 2016GL068712.

Son, S.-W., S.-Y. Kim, and S.-K. Min, 2018: Widening of the Hadley cell from Last Glacial Maximum to future climate. J. Climate, 31, 267-281, https://doi.org/10.1175/ JCLI-D-17-0328.1.

Staten, P. W., and T. Reichler, 2014: On the ratio between shifts in the eddy-driven jet and the Hadley cell edge. Climate Dyn., 42, 1229-1242, https://doi.org/10.1007/ s00382-013-1905-7.

Tandon, N. F., E. P. Gerber, A. H. Sobel, and L. M. Polvani, 2013: Understanding Hadley cell expansion versus contraction: Insights from simplified models and implications for recent observations. J. Climate, 26, 4304-4321, https://doi.org/10.1175/ JCLI-D-12-00598.1.

Thuburn, J., and G. C. Craig, 2000: Stratospheric influence on tropopause height: The radiative constraint. J. Atmos. Sci., 57, 17-28, https://doi.org/10.1175/1520-0469(2000)057<0017: SIOTHT $>2.0 . \mathrm{CO} ; 2$.

Trenberth, K. E., and J. M. Caron, 2001: Estimates of meridional atmosphere and ocean heat transports. J. Climate, $\mathbf{1 4}$ 3433-3443, https://doi.org/10.1175/1520-0442(2001)014<3433: EOMAAO $>2.0 . \mathrm{CO} ; 2$.

Vallis, G. K., P. Zurita-Gotor, C. Cairns, and J. Kidston, 2015: Response of the large-scale structure of the atmosphere to global warming. Quart. J. Roy. Meteor. Soc., 141, 1479-1501, https://doi.org/10.1002/qj.2456.

Walker, C. C., and T. Schneider, 2006: Eddy influences on Hadley circulations: Simulations with an idealized GCM. J. Atmos. Sci., 63, 3333-3350, https://doi.org/10.1175/JAS3821.1.

Winton, M., 2003: On the climatic impact of ocean circulation. J. Climate, 16, 2875-2889, https://doi.org/10.1175/ 1520-0442(2003)016<2875:OTCIOO > 2.0.CO;2.

Xu, K.-M., and K. A. Emanuel, 1989: Is the tropical atmosphere conditionally unstable? Mon. Wea. Rev., 117, 1471-1479, https://doi.org/10.1175/1520-0493(1989)117<1471: ITTACU>2.0.CO;2.

Zurita-Gotor, P., and R. S. Lindzen, 2007: Theories of baroclinic adjustment and eddy equilibration. The Global Circulation of the Atmosphere, T. Schneider and A. H. Sobel, Eds., Princeton University Press, 22-46. 